\title{
Reduced Cortical BDNF Expression and Aberrant Memory in Carf Knock-Out Mice
}

\author{
Kelli A. McDowell, ${ }^{1 *}$ Ashley N. Hutchinson, ${ }^{1 *}$ Sarah J.E. Wong-Goodrich, ${ }^{2}$ Matthew M. Presby, ${ }^{1}$ Dan Su, ${ }^{1}$ \\ Ramona M. Rodriguiz, ${ }^{3,4}$ Krystal C. Law, ${ }^{\dagger}{ }^{\dagger}$ Christina L. Williams, ${ }^{2}$ William C. Wetsel, ${ }^{1,3,4,5}$ and Anne E. West ${ }^{1}$ \\ ${ }^{1}$ Department of Neurobiology, ${ }^{2}$ Department of Psychology and Neuroscience, ${ }^{3}$ Department of Psychiatry and Behavioral Sciences, ${ }^{4}$ Mouse Behavioral and \\ Neuroendocrine Analysis Core Facility, and ${ }^{5}$ Department of Cell Biology, Duke University Medical Center, Durham, North Carolina 27710, and ${ }^{6}$ Division of \\ Neuroscience, Children's Hospital, Boston, Massachusetts 02115
}

Transcription factors are a key point of convergence between the cell-intrinsic and extracellular signals that guide synaptic development and brain plasticity. Calcium-response factor (CaRF) is a unique transcription factor first identified as a binding protein for a calciumresponse element in the gene encoding brain-derived neurotrophic factor (Bdnf). We have now generated Carf knock-out (KO) mice to characterize the function of this factor in vivo. Intriguingly, Carf KO mice have selectively reduced expression of $B d n f$ exon IV-containing mRNA transcripts and BDNF protein in the cerebral cortex, whereas BDNF levels in the hippocampus and striatum remain unchanged, implicating CaRF as a brain region-selective regulator of BDNF expression. At the cellular level, Carf KO mice show altered expression of GABAergic proteins at striatal synapses, raising the possibility that CaRF may contribute to aspects of inhibitory synapse development. Carf KO mice show normal spatial learning in the Morris water maze and normal context-dependent fear conditioning. However they have an enhanced ability to find a new platform location on the first day of reversal training in the water maze and they extinguish conditioned fear more slowly than their wild-type littermates. Finally, Carf KO mice show normal short-term (STM) and long-term memory (LTM) in a novel object recognition task, but exhibit impairments during the remote memory phase of testing. Together, these data reveal novel roles for CaRF in the organization and/or function of neural circuits that underlie essential aspects of learning and memory.

\section{Introduction}

Activity-dependent plasticity is an essential feature of the brain, allowing neuronal structure and function to adapt to changes in the environment. Changes in synaptic activity drive long-lasting alterations in neuronal function in part by regulating the expression of genes whose products affect cell morphology, synaptic function, and/or intrinsic excitability (Greer and Greenberg, 2008). Intracellular calcium signaling pathways are essential intermediates in this process, converging in the nucleus to regulate the expression and/or function of transcription factors (West et al., 2002).

In addition to receiving information from synapses, many activity-regulated transcription factors also contribute to

\footnotetext{
Received Aug. 13, 2009; revised April 2, 2010; accepted April 9, 2010.

This work was supported by National Institutes of Health (NIH) Grant R01-DA022202 (A.E.W.), a grant from the Whitehall Foundation (A.E.W.), the NIH Postbaccalaureate Research Education Program, the National Science Foundation Research Experiences for Undergraduates, Howard Hughes Medical Institute research training programs at Duke University, and support for the Gene Manipulation Facility of The Children's Hospital, Boston, through the Mental Retardation and Developmental Disabilities Research Center (Grant NIH-P30-HD18655). This work is dedicated to the memory of Krystal C. Law. We are deeply grateful to Michael E. Greenberg for intellectual support and the generous contribution of reagents. We thank Tam Thompson, Linda Hu, Janine Zieg, Lora Sweeney, Jon Zurawski, Monica Hamilton, Chase Palisch, Jie Deng, and Caroline Kim for technical support and advice on experiments, and James 0 . McNamara for critical reading of this manuscript.

*K.A.M. and A.N.H. contributed equally to this work.

${ }^{\dagger}$ Deceased February 2008

Correspondence should be addressed to Anne E. West, Department of Neurobiology, Duke University Medical Center, Box 3209, Durham, NC 27710. E-mail: west@neuro.duke.edu.

D0I:10.1523/JNEUROSCI.3997-09.2010

Copyright $\odot 2010$ the authors $\quad 0270-6474 / 10 / 307453-13 \$ 15.00 / 0$
}

experience-dependent synapse development and remodeling. For example, calcium-dependent activation of the transcription factor MEF2 induces the expression of gene products that subsequently drive the elimination of excitatory synapses (Flavell et al., 2006), whereas activity-dependent expression of the transcription factor NPAS4 controls the number of GABAergic synapses that form on excitatory neurons (Lin et al., 2008). Importantly, these transcriptional effects on synapses may have consequences for learned behaviors. For example, RNA interference-mediated knockdown of MEF2 in the striatum not only increases dendritic spine density, but also attenuates persistent behavioral sensitization after chronic cocaine, suggesting a link between MEF2's effects on synapses and the behavioral consequences of psychostimulant exposure (Pulipparacharuvil et al., 2008). Hence, study of transcriptional regulators that link environmental stimuli with synapses may yield new insights into cognition.

Calcium-response factor ( $\mathrm{CaRF}$ ) is a unique transcription factor that was first cloned and characterized as a binding protein for a calcium-response element (CaRE1) that is required for activitydependent transcription from promoter IV of the brain-derived neurotrophic factor (Bdnf) gene (Tao et al., 2002). CaRF shares no homology with other transcription factors, however, it is a nuclear, sequence-specific DNA binding domain protein, and it can act as a CaRE1-dependent transcriptional activator. Given that BDNF is a secreted neurotrophic factor that has numerous effects on synapses (Poo, 2001), the evidence that CaRF can regulate transcription of $B d n f$ raised the possibility that CaRF might 
contribute to neural development and/or plasticity. However, the biological functions of CaRF have remained entirely unknown.

To study CaRF in vivo, we generated a CaRF-specific antibody and Carf knock-out (KO) mice. Here we demonstrate a role for $\mathrm{CaRF}$ in the transcriptional regulation of $B d n f$, and surprisingly, we find that this requirement for CaRF is both brain-region and stimulus selective. At the cellular level, we find that Carf KO mice have altered expression of GABAergic synaptic proteins in the striatum, raising the possibility that CaRF may contribute to aspects of inhibitory synapse development. Finally, through a series of behavioral tasks, we demonstrate that Carf KO mice display alterations in discrete aspects of spatial, emotional, and recognition memory. Together, these data demonstrate that CaRF is a biologically important transcription factor in the CNS and suggest that CaRF-dependent programs of gene transcription may contribute to development and/or plasticity of the neural circuits that underlie learning and memory.

\section{Materials and Methods}

Generation of Carf knock-out mice and genotyping. All oligonucleotides used in this study were synthesized by Integrated DNA Technologies (Coralville, IA) and are listed in supplemental Table S1 (available at www.jneurosci.org as supplemental material). To generate the genomic targeting vector, a $129 S 4$ bacterial artificial chromosome (BAC) library (Incyte Genomics) was screened using Carf primers against intron 7 and exon 8. BAC 27839 was selected as a template for the generation of a 5.3 $\mathrm{kB}$ piece of Carf genomic DNA containing intron 7 through exon 9 (base pair 37713501 to 37719853 of mouse chromosome 1, NT_039170.7, July 2007 build, http://genome.ucsc.edu), which was cloned in Bluescript (pBKS-) from EcoRI to NotI. Using recombineering techniques (Angrand et al., 1999), an FRT-flanked pGK-Neo cassette and a single loxP site were placed $133 \mathrm{bp} 5^{\prime}$ to the beginning of exon 8 , and a second loxP site was placed $425 \mathrm{bp} 3^{\prime}$ to the end of exon 8 . The Carf targeting vector was electroporated into 129S4/SvJae embryonic stem (ES) cells, clones were selected for integration with $150 \mu \mathrm{g} / \mathrm{ml} \mathrm{G} 418$, and genomic DNA from $\sim 1200$ individual neomycin-resistant clones was screened by southern blotting. Two properly targeted clones were identified. One clone (\#112) showed a normal karyotype and was injected into C57BL/6J blastocysts, yielding three chimeric pups. Chimeras were mated to C57BL/6J wild-type (WT) mice (The Jackson Laboratory) and germline transmission from two chimeras was confirmed by PCR genotyping of tail biopsies from the offspring. These mice were crossed to a 129S4/SVJae Flp deleter line (The Jackson Laboratory) (Farley et al., 2000), and germline recombination of the pGK-Neo cassette was confirmed by PCR. Finally, Carf ${ }^{2 l o x, N e o-1+}$ mice were crossed to transgenic EIIa-Cre mice on a mixed C57BL/6-FVB background (The Jackson Laboratory) (Lakso et al., 1996), and germline recombination of Carf exon 8 was confirmed by PCR genotyping of tail biopsies. Mice were maintained on a mixed genetic background, and in all experiments Carf KOs were compared with their heterozygous (HET) and WT littermates. All experiments were conducted with an approved protocol from the Duke University Institutional Animal Care and Use Committee.

Luciferase assays. 293T cells were cultured and transfected as described previously (Tao et al., 2002). Luciferase assays were performed $2 \mathrm{~d}$ after transfection using the Dual Assay Luciferase kit (Promega). Cotransfected thymidine kinase (TK)-renilla luciferase was used to normalize samples for transfection efficiency and sample handling. All data presented are the average of at least three measurements from each of at least two independent experiments. To generate the CaRF consensus CaRFbinding element (cCaRE) and mutant $(\mathrm{m}) \mathrm{CaRE}$ reporters, three $21 \mathrm{bp}$ repeats (supplemental Table S1, available at www.jneurosci.org as supplemental material) were cloned into the firefly luciferase expression vector pOF-luc (a gift from J. Liu, Johns Hopkins University, Baltimore, MD) at the HindIII and XhoI sites.

Preparation of recombinant mouse CaRF and antibody purification. Full-length mouse Carf(NM_139150) was amplified by PCR and cloned in the baculoviral expression vector pAcGHLT-A (PharMingen/BD Bio- sciences) to generate an N-terminal glutathione $S$-transferase (GST)CaRF fusion protein. Recombinant baculovirus was produced by Orbigen and then amplified in $S f 9$ cells. For protein production, virus was incubated with $S f 21$ cells grown in suspension in Hink's TNM-FH medium (JRH Biosciences), 10\% insect-tested FBS (Sigma), $1 \times$ Pluronic F-68 (Sigma), and penicillin/streptomycin (Pen/Strep; Sigma). Seventytwo hours later, cells were spun down and lysed in $50 \mathrm{~mm}$ Tris, $\mathrm{pH} 8.0$, $150 \mathrm{~mm} \mathrm{NaCl}_{2}, 0.7 \%$ 3-[(3-cholamidopropyl)dimethylammonio]1-propanesulfonate (CHAPS), 1\% Triton X-100, and $5 \mathrm{~mm}$ DTT. GST-CaRF was purified from the lysate by incubation with glutathioneagarose beads, and eluted with $20 \mathrm{~mm}$ reduced glutathione (Sigma). Purified GST-CaRF protein was injected into three rabbits (Covance) and screened by Western blotting for detection of recombinant CaRF. Antiserum from one rabbit (\#4510) was purified by ammonium sulfate precipitation of IgG, and then it was passed over an Affigel 15 column (Bio-Rad) on which we had mounted purified GST-CaRF. The flowthrough was discarded, and the antibody was eluted with glycine, dialyzed, and stored in PBS with glycerol.

Nuclear extracts. Nuclear extracts were prepared following a high-salt extraction procedure (Tao et al., 1998). Protein concentration was determined by protein assay (Bio-Rad).

Western blotting. Ten micrograms of nuclear extract or $20 \mu \mathrm{g}$ of striatal lysate was loaded on $8-10 \%$ SDS-PAGE gels for separation and transferred to polyvinylidene fluoride (PVDF) membrane. After blocking, primary antibodies were incubated for $60 \mathrm{~min}$ at room temperature, and secondary antibodies conjugated to HRP (Jackson ImmunoResearch) were used at 1:10,000. Bands were visualized by reacting blots with ECL (Pierce) and exposing to film. For quantitation, multiple exposures were taken to establish the linear range, and films were scanned for densitometry using ImageJ (http://rsbweb.nih.gov/ij/). All bands were normalized to actin in the same sample as a loading control. Primary antibodies used in this study include rabbit anti-CaRF, 1:500 (\#4510, present study); rabbit anti-Histone H3, 1:5000 (Millipore; catalog \#070-690); mouse anti-MEF2D, 1:1000 (BD Biosciences; catalog \#610774); rabbit anticAMP response element-binding protein (anti-CREB), 1:1000 (Millipore; catalog \#06-863); rabbit anti-synaptophysin, 1:10,000 (Zymed/ Invitrogen; catalog \#18-0130); rabbit anti-DARPP-32, 1:1000 (Millipore Bioscience Research Reagents; catalog \#AB1656); mouse anti-GAD-67, 1:5000 (Millipore Bioscience Research Reagents; catalog \#MAB5406); mouse anti-GABA ${ }_{A} \beta 2 / 3,1: 500$ (Millipore Bioscience Research Reagents; catalog \#MAB341); rabbit anti-GABA ${ }_{\mathrm{A}} \gamma 2$, 1:500 (Millipore Bioscience Research Reagents; catalog \#AB5954); mouse anti-GAD-65, 1:500 (Millipore; catalog \#MAB351); mouse anti-NR1, 1:1000 (Affinity Bioreagents; catalog \#OMA1-04010); rabbit anti-SAPAP3, 1:1000 (a gift from Dr. G. Feng, Duke University Medical Center, Durham, NC); mouse anti-PSD-95, 1:1000 (Millipore Bioscience Research Reagents; catalog \#MAB1596); and mouse anti-Actin, 1:1000 (Millipore Bioscience Research Reagents; catalog \#MAB1501).

Electrophoretic mobility shift assay. Two to five micrograms of nuclear extracts were incubated with $50 \mathrm{fmol}{ }^{32} \mathrm{P}$ end-labeled oligonucleotide probes for $20 \mathrm{~min}$ at room temperature before separation on a $6 \%$ nondenaturing acrylamide gel in Tris-borate buffer, $\mathrm{pH}$ 7.5. In competition assays, unlabeled probes were added to nuclear extracts in 100-fold molar excess to the radiolabeled probe for $30 \mathrm{~min}$ before addition of the labeled probe. Gels were dried and visualized by PhosphorImager, and shifts were quantitated relative to probe intensity in the same lane using the ImageQuant image analysis program (GE Healthcare).

Mouse embryonic fibroblasts. Mouse embryonic fibroblasts were generated as described previously $(\mathrm{Xu}, 2005)$ from individual embryonic day 13.5 (E13.5) embryos of a Carf HET by HET cross. For luciferase assays, $1 \times 10^{6}$ cells were transfected using AMAXA (Lonza; catalog \#VCA-1003) following the manufacturer's instructions and using program A-23.

RNA harvesting and real-time PCR. Brain tissue was rapidly dissected on ice, snap frozen in liquid nitrogen, and stored at $-80^{\circ} \mathrm{C}$. RNA was harvested using the Absolutely RNA kit (Stratagene). Five hundred nanograms of RNA were used for reverse transcription with oligo dT primers and Superscript II (Invitrogen). cDNA was used for quantitative PCR of gene transcripts (Power SYBR Green, ABI 7300 real-time PCR machine; Applied Biosystems) with the intron-spanning primers listed in 
supplemental Table S1 (available at www.jneurosci.org as supplemental material). Each sample was measured in triplicate, and expression of the housekeeping gene Gapdh was used as a normalizing control for RNA quantity and sample processing. All data shown are derived from at least three samples from each of at least two independent experiments.

Neuronal and glial cell cultures. Neuron-enriched cultures were generated from E16 CD1 mouse embryos (Charles River Laboratories). Briefly, the cortex was dissected, cells were dissociated with papain (Worthington Biochemicals), and the cell suspension was plated on poly-D-lysine (PDL)-coated dishes or glass coverslips in Neurobasal medium with B27 supplements (Invitrogen) and Pen/Strep. For analysis of CaRF expression, cultures were treated on day in vitro 5 (DIV5) with $1 \mu \mathrm{M}$ tetrodotoxin (TTX; Sigma) or $55 \mathrm{~mm} \mathrm{KCl}$ in an isotonic solution (Tao et al., 2002). Glial cultures were generated by dissociating postnatal day 0 (P0)/P1 cortices and plating the cells on tissue culture dishes in DMEM with 5\% FBS and Pen/Strep. Cells were fed and passaged over a period of 3 weeks before RNA harvesting. For immunocytochemistry of mixed neural/glial cultures, dissociated cortical cells from P0 embryos were plated on PDL-coated glass coverslips in Neurobasal medium with B27 supplements; AraC was added to $10 \mu \mathrm{m}$ beginning on DIV2. At DIV10, the cells were fixed for $10 \mathrm{~min}$ in $4 \%$ paraformaldehyde, blocked with $16 \%$ goat serum, and permeabilized with $0.2 \%$ Triton X-100. Primary antibodies were incubated overnight at $4^{\circ} \mathrm{C}$, and after washing, fluorescent secondary antibodies were applied for $60 \mathrm{~min}$ at room temperature at 1:500. Hoechst dye was included in the final washes to label DNA. Antibodies used are purified rabbit anti-CaRF (\#4510, present study), 1:100, and chicken anti-MAP2, 1:400 (Millipore Bioscience Research Reagents; catalog \#AB5543).

$B D N F$ protein measurements. Brain extracts from frontal cortex, hippocampus, or striatum of Carf WT and KO mice were prepared as described previously (Hong et al., 2008). BDNF protein was measured using a two-site ELISA using the BDNF Emax ImmunoAssay System (Promega). All samples were measured in triplicate and compared against a standard curve on the same plate.

Synapse immunohistochemistry. Six-month-old adult Carf KO mice or their WT littermates were anesthetized and transcardially perfused with $4 \%$ paraformaldehyde in $0.1 \mathrm{~m}$ PBS. Brains were postfixed in $4 \%$ paraformaldehyde/PBS overnight, and then sunk in 30\% sucrose/PBS overnight. Coronal sections ( $40 \mu \mathrm{m}$ thick) were cut on a freezing microtome, and brain regions were identified by reference to anatomical landmarks. To minimize variation in immunostaining across treatment groups, sections from individual mice were first placed and spread into a Petri dish filled with PBS, and then photographed with a high-resolution digital camera (Sony DSC-H1). All sections were then mixed for immunolabeling and processed within a single chamber. Sections were incubated with primary antibodies overnight at $4^{\circ} \mathrm{C}$ and with fluorescent-conjugated secondary antibodies for $1 \mathrm{~h}$ at room temperature. Nuclei were labeled with Hoechst dye (Sigma) to facilitate anatomical localization of structures, sections were mounted and coverslipped, then fluorescent images were captured on a Leica DMI4000 inverted fluorescence microscope using a Cascade 512B camera. Digital images were quantified using MetaMorph 7.0 Image Analysis software (Molecular Devices). All images within one experiment were taken with a constant exposure time and aperture, and quantified using a single threshold value. To reduce variation between mice, we measured expression of synaptic markers from a constant-sized region across the shell of the nucleus accumbens (NAc). Four separate images from each brain were captured with a $63 \times$ oil lens. Images were captured in a z-stack in MetaMorph and subjected to threedimensional (3D) deconvolution processing using AutoQuant X2.1.1 software (Media Cybernetics). After 3D deconvolution, a four consecutive image stack (equivalent to $2 \mu \mathrm{m}$ thickness) was merged using the Average Stack Arithmetic module in MetaMorph. The merged images were then quantitated using the Count Nuclei module in MetaMorph to evaluate both numbers of synaptic punctae as well as the integrated intensities of these punctate spots of immunoreactivity. Punctae were defined in MetaMorph as local regions two to four pixels in size with intensity a set threshold above the local background. Primary antibodies used in this study include mouse anti-GAD65 (1:1000; Millipore) and rabbit anti-synaptophysin (1:1000; Zymed).
SHIRPA phenotypic screen. Naive male CaRFWT $(n=10)$, HET $(n=20)$, and $\mathrm{KO}(n=12)$ littermates were subjected to a standard observational SHIRPA test for purposes of comprehensive behavioral and functional profiling (Rogers et al., 1997). All parameters were scored by two investigators blind to the genotype of the mice. Briefly, each mouse was first assessed by observing undisturbed behavior in a viewing jar for the features listed in supplemental Table S2 (available at www.jneurosci.org as supplemental material). Next, each mouse was transferred to an arena to examine transfer arousal and open-field behavior, as well as responses to a sequence of manipulations using tail suspension and a grid laid across the width of the arena. Finally, each mouse was restrained in a supine position to record autonomic behaviors before measurement of the righting reflex. Throughout this procedure, vocalization, urination, and general fear, irritability, and aggression were recorded.

Morris water maze. After the SHIRPA screen, male CaRFWT $(n=10)$, HET $(n=20)$, and $\mathrm{KO}(n=12)$ littermates 2.5 to 4 months of age received $7 \mathrm{~d}$ of water maze training during the light phase of their light/ dark cycle. The maze consisted of a circular pool $\sim 1.2 \mathrm{~m}$ in diameter and filled with room-temperature water. A circular platform $10 \mathrm{~cm}$ in diameter was submerged $2 \mathrm{~cm}$ below the surface of the water, and the water was clouded by nontoxic powered tempera paint to ensure that the mice could not see the platform. The pool was located in a well-lit room $(\sim 5.8 \times 2.6 \mathrm{~m}$ in dimension $)$ with salient extramaze cues, such as a table with a computer, shelving that contained large objects, pictures of large black shapes adhered to a curtain and room walls, a large metal trash bin, and the experimenter who sat in a chair near the computer. The water maze was divided into four quadrants (north, south, east, and west) with the hidden platform located in the center of one target quadrant. For all training trials, mice were placed in a random start location in the pool (north, south, east, or west) facing the wall of the pool and given $60 \mathrm{~s}$ to locate the hidden platform. If a mouse did not find the platform by the end of $60 \mathrm{~s}$, it was gently guided to the platform. Mice were allowed to sit on the platform for $15 \mathrm{~s}$ after climbing on to it. After each training trial, mice were removed from the water maze, dried with a towel, allowed to rest for $60 \mathrm{~s}$, and then immediately began the next trial.

On days $1-4$, mice received four training trials per day on a placelearning water maze task, where the hidden platform remained in the same spatial location for each trial. On day 4, mice received a single immediate probe trial in between trials 2 and 3. During probe trials, the platform was removed, and mice were allowed to swim for $60 \mathrm{~s}$. After the probe trial, each mouse completed trials 3 and 4 with the platform present to prevent extinction of prior learning. Twenty-four hours later, on day 5 , mice received a single $24 \mathrm{~h}$ probe trial, followed by three additional training trials and then a single curtain trial. During the curtain trial, a large curtain was drawn around the maze to eliminate all extramaze cues from view. This allowed us to determine whether mice were using extramaze spatial cues to find the hidden platform. On day 6, mice received four training trials on a reversal learning task, where the platform location was moved to a new location in a different quadrant in the pool. Finally, on day 7 , each mouse received four training trials on a visible platform task where the platform was raised above the water line and labeled with white tape. On each trial, the location of the platform changed.

For all trials, performance on the task was recorded using a computerized tracking system (HVS Image). For training trials, latency (seconds) to locate the platform was recorded as a measure of spatial learning. For probe trials, the percentage of time spent searching in each quadrant was a measure of spatial memory. To determine the search strategy of each mouse when initially challenged with learning a new platform location during reversal learning, we also recorded percentage of time spent in each quadrant during the first trial of reversal learning.

Fear conditioning. Mice were tested for context fear conditioning and extinction using methods described previously for the mouse (Schmalzigaug et al., 2009). Mice (8 WT and $11 \mathrm{KO}$ ) were examined at the same time each day, between 10:00 A.M. and 1:00 P.M. On day 0 (conditioning), the mice were placed into a Med Associates fear conditioning chamber $(26 \times$ $22 \times 12 \mathrm{~cm}$ ) illuminated with a $100 \mathrm{~mA}$ house light. After $2 \mathrm{~min}$, a $72 \mathrm{~dB}$, $2900 \mathrm{~Hz}$ tone [conditioned stimulus (CS)] was presented for $30 \mathrm{~s}$. The CS terminated simultaneously with a single $2 \mathrm{~s}, 0.4 \mathrm{~mA}$ scrambled foot shock 
[unconditioned stimulus (UCS)]. Animals remained in the conditioning chamber for $30 \mathrm{~s}$, after which they received a second CS-UCS pairing and were returned to the home cage after $30 \mathrm{~s}$. Contextual fear conditioning was assessed $24 \mathrm{~h}$ later (day 1 ) over $5 \mathrm{~min}$ in the absence of the CS or UCS. Cued fear conditioning was evaluated $48 \mathrm{~h}$ after initial conditioning (i.e., day 2). Mice were placed into a neutral environment for $2 \mathrm{~min}$, and the CS was presented continually over the next $3 \mathrm{~min}$. Extinction of contextual fear conditioning began on day 3 . It included the same procedures as described for day 1 of testing and was continued for 13 consecutive days, by which time freezing behavior had reached the level of preconditioning on day 0 and did not change over 3 consecutive days. Freezing behavior was defined the absence of all movement by the animal other than that required for respiration. All behaviors were video recorded. The recordings were scored subsequently by trained observers using Noldus Observer 5 (Noldus Information Technology). All observers were blind to genotype. The results are presented as the percentage of time spent freezing at conditioning, testing, and extinction.

Novel object recognition. Novel object recognition was examined using methods described previously for the mouse (Rodriguiz et al., 2007). Before testing, each mouse was habituated to an empty Plexiglas arena $(48 \times 22 \times 18 \mathrm{~cm})$ for 3 consecutive days. On the first day of testing, mice were exposed to two identical objects (T1 and T2; $4 \times 4 \times 2 \mathrm{~cm}$ ) placed at opposite ends of the arena. The animals were permitted to explore the arena and the objects for $10 \mathrm{~min}$ before being returned to the home cage. After $20 \mathrm{~min}$, mice were returned to the arena for a short-term memory test, where they were presented for $10 \mathrm{~min}$ with one of the familiar objects (T1) and a novel object (N1) of similar dimensions. Twenty-four hours later, mice were tested for long-term memory. Each animal was returned to the arena for $10 \mathrm{~min}$ with the familiar object (T1) and a second novel object (N2). Ten days later, mice were tested for remote memory. Each animal was returned to the arena for $10 \mathrm{~min}$ and was presented with the familiar object (T1) and another novel object (N3). For each test, objects were always placed in the same two locations; however, the location of the novel object relative to the familiar object was randomized for each test across mice. All tests were conducted under indirect 80-100 lux illumination between 10:00 A.M. and 2:00 P.M., and behaviors were videotaped and scored subsequently with Noldus Ethovision XT 7.0 (Noldus Information Technology). The automated Ethovision XT software program used multiple-point tracking to identify the main body axis of the animal, and it tracked the location of the nose relative to each object. Contact with a given object was defined as the mouse approaching the object nose first, with the nose being within $1 \mathrm{~cm}$ of the object boarder. Duration and frequency of nose contacts with each object were scored. Preference for the novel object was calculated by subtracting the time spent with the familiar object (T1) from the time spent with the novel object (N1, N2, or N3) and dividing this amount by the total time spent with both objects. Positive scores signified preference for the novel object, negative values indicated preference for the familiar object, and scores of "0" denoted no preference for either object. To confirm that the Ethovision XT program was scoring videos accurately, several test videos were randomly selected and analyzed by trained observers using Noldus Observer 5.0 (Noldus Information Technology). Kappa scores between automated scoring and live coder scoring for duration and contacts with objects exceeded 0.92 .

Statistical analyses. The results are presented as means and SEMs. The mRNA and protein expression data were analyzed by unpaired two-tailed $t$ test using GraphPad software. The statistical analyses of behavioral data were performed using SPSS 11. For object testing, repeated-measures ANOVAs (RMANOVAs) were conducted within each test day (STM, LTM, and remote memory) for duration spent with objects, frequency of contacts with objects, and preference scores for the within-subject effects of object (familiar and novel) and the between-subjects effect of genotype with the interaction between these two main effects. For fear conditioning and extinction, the percentage of time freezing was assessed using RMANOVA with within-subject effects of test day, between-subjects effects of genotype, and the interactions. In all cases, a posteriori analyses were conducted using Bonferroni-corrected pairwise comparisons; $p<$ 0.05 was considered statistically significant.

\section{Results}

\section{Generation of Carf knock-out mice and validation of a CaRF-specific antibody}

To investigate the physiological functions of CaRF in vivo, we generated a Carf KO mouse. The Carf gene is comprised of 16 exons spanning $52.7 \mathrm{kB}$ of mouse chromosome 1 (Fig. 1A) (Mus musculus chromosome 1, 60155125-60207878, July 2007 assembly, http://genome.ucsc.edu). The locus also encodes a shorter Carf variant that utilizes an alternative polyadenylation site in the intron following exon 8 (orthologous to the short variant of human ALS2CR8; GenBank accession number AB053310). We chose to target exon 8 for deletion because this exon encodes an evolutionarily conserved domain in CaRF that is required for DNA binding (Tao et al., 2002). loxP sites were placed around exon 8, and an FRT-flanked pGK-Neo cassette was inserted just 5' to the loxP site in intron 7 (Fig. $1 A$ ). The targeting vector was introduced into ES cells, and homologous recombination at the Carflocus was validated by Southern blotting (Fig. $1 B$ ). Germline transmission was confirmed by PCR (Fig. 1C), the Neo cassette was excised by crossing Carflox-Neo/+ mice to a Flp deleter strain (Fig. 1D) (Farley et al., 2000), and then Carflox/+ mice were crossed to a Cre deleter strain (Lakso et al., 1996) to obtain germline recombination at the Carf locus (Fig. 1E). Heterozygous $\mathrm{Carf}^{+/-}$mice were maintained on a mixed 129/C57BL6 background and in all subsequent experiments; Carf-/- (KO) mice were compared to wild-type $\operatorname{Carf}^{+/+}$littermates as control.

Carf mRNA is still detected in KO mice, however this mRNA is shorter than WT Carf by an amount consistent with the deletion of exon 8 (Fig. $1 F, G$ ). Extensive sequencing across the deletion revealed no evidence of alternative exons or splicing that would generate novel in-frame transcripts (data not shown). We tested the consequences of potential residual protein expression from the Carf locus, but found no evidence that CaRF variants lacking exon 8 were capable of driving CaRE1-dependent transcription or acting in a dominant negative fashion to suppress CaRF-dependent transcription (Fig. $1 H$ ). Although we cannot exclude that putative functions of CaRF mediated solely by the $\mathrm{N}$-terminal domain may not be disrupted in the Carf exon 8 deleted mice, we anticipate that these mice are null for the nuclear and transcriptional functions of CaRF.

To validate that Carf ${ }^{-} \mathrm{KO}$ mice lack functional nuclear CaRF protein, we first isolated nuclear extracts from the brains of Carf WT or KO mice and assayed for CaRF expression by Western blotting with a polyclonal antiserum raised against purified recombinant full-length mouse CaRF. Four immunoreactive bands ranging in size from $85-100 \mathrm{kDa}$ are seen in nuclear extracts from WT mice, and these are selectively lost in extracts from the KO mice, suggesting that all four protein species are encoded by the Carf locus (Fig. 2A). Although the specific molecular nature of these multiple CaRF variants are not known, they may represent products of alternatively spliced Carf transcripts or differentially posttranslationally modified CaRF proteins. Because CaRF is a sequence-specific DNA binding protein, we next asked whether Carf KO mice retain any binding activity for a DNA probe containing a high-affinity CaRF binding sequence (supplemental Table S1, available at www.jneurosci.org as supplemental material) (A. E. West, unpublished data). When a radiolabeled DNA probe containing the consensus CaRF binding site is incubated with nuclear extracts from Carf WT mice and separated on a nondenaturing gel in an electrophoretic mobility shift assay (EMSA), a slowly migrating band is visible, indicating the association with a binding protein (Fig. 2 B). By contrast, no slowly migrating bands 


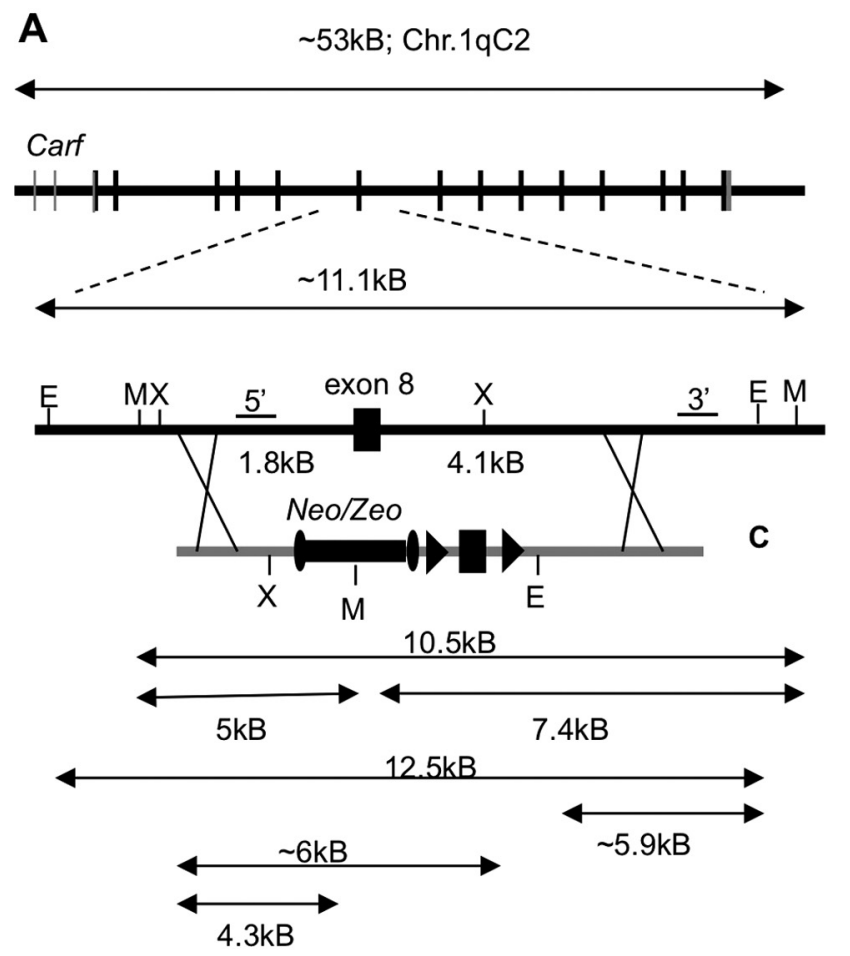

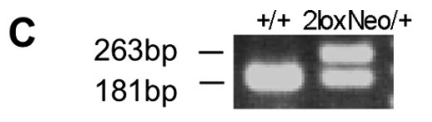

D

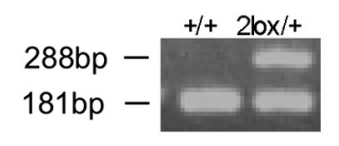

WT(+)

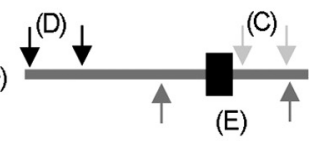

$2 \mathrm{loxNeO}$

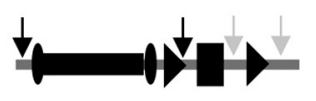

E
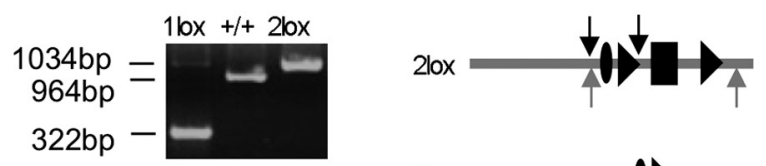

1 lox

$10 x$
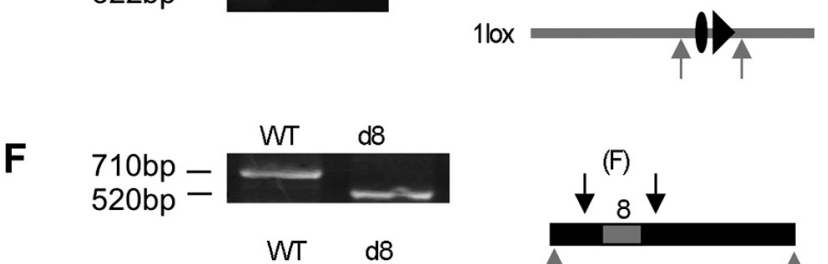

G
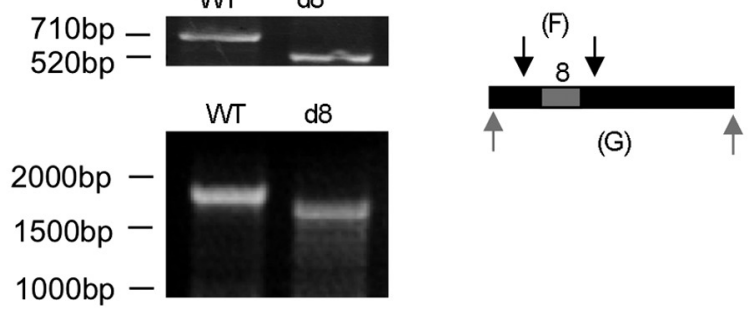

H

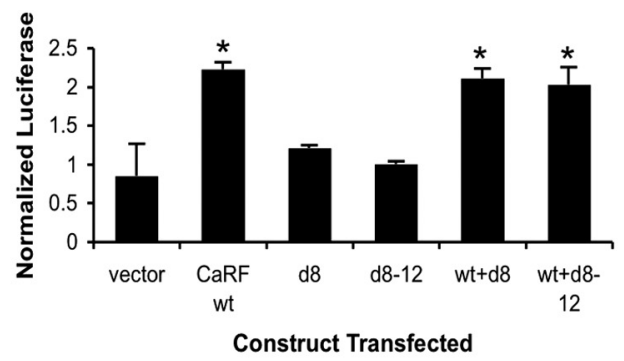

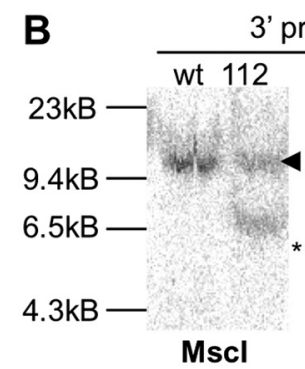

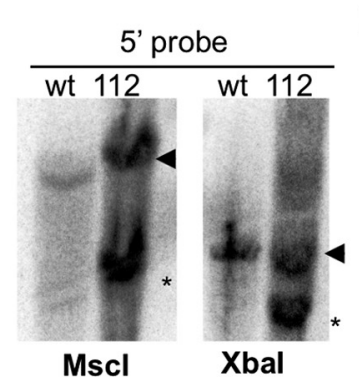

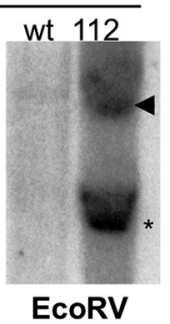

Figure 1. Generation of a Carf exon 8 KO mouse. A, Genomic organization of the Mus musculus Carf gene, which spans 53 kB on chromosome 1. Boxes represent exons. E, EcoRV; M, Mscl; X, Xbal. Ovals show FRT sites, and triangles show loxP sites. The box under Neo/Zeo represents the position of the neomycin resistance gene in the targeting vector. The numbers and arrows indicate the size of genomic fragments generated on Southern blotting by cleavage with the indicated enzymes. B, Southern blot analysis of ES cell line 112. Positions of the $5^{\prime}$ and $3^{\prime}$ probes are indicated in $A$. WT or ES clone 112 with targeted mutation of Carf gene. Arrowheads indicate the WT allele, asterisks show the targeted allele. C-E, PCR analysis of targeted clone 112. C, Primers across the $3^{\prime}$ loxP site show the $40 \mathrm{bp}$ insertion. The positions of the primers are indicated by the light gray arrows. $D$, Recombination of the Neomycin resistance cassette. The positions of the primers are indicated by the black arrows. $\boldsymbol{E}$, Deletion of exon 8 with primers that cross the deletion. The positions of the primers are indicated by the medium gray arrows. $\boldsymbol{F}, \boldsymbol{G}, \mathrm{PCR}$ analysis of cDNA made from neurons of nonrecombined (WT) or Cre recombined (d8) targeted mice. F, Primers spanning from exons 7-9 (black arrows). G, Primers spanning the full coding region (gray arrows) show a single band $\sim 190$ bp shorter than full-length Carf. $\boldsymbol{H}, B d n f$ promoter IV enhanced luciferase reporter gene expression in transfected 293T cells with cotransfected CaRF deletion constructs. d8, Deletion of exon 8; $\mathrm{d} 8-12$, deletion of exons $8-12$. Error bars represent SEM. All data are the result of at least three independent replicates. ${ }^{*} p<0.05$.

are observed when the probe is incubated with nuclear extracts from Carf KO brains, demonstrating that these mutants lack all CaRF-like binding activity. As a control for preparation of the nuclear extracts, we show that both WT and Carf KO nuclear extracts display similar amounts of binding activity for a DNA probe with binding sites for the USF family of transcription factors (Chen et al., 2003) (Fig. 2C).

Finally, to quantify the effects of Carf exon 8 deletion on CaRF-dependent transcription, we transfected primary embryonic fibroblasts from CaRF WT, HET, or KO mice with a CaRFdependent firefly luciferase reporter plasmid. Carf HET cells express $42 \pm 7 \%$ as much Carf mRNA as WT cells and show a corresponding reduction in CaRF protein (Fig. 2D). When normalized to a cotransfected control TK-renilla luciferase plasmid to scale CaRF-dependent expression in each cell line, HET cells show only $33.6 \pm 12 \%$ of the CaRF-dependent gene expression seen in WT cells, indicating that the loss of CaRF protein we detect is accompanied by a corresponding decrease in CaRFdependent gene expression. These data demonstrate that our Carf KO mouse lacks both nuclear CaRF protein and CaRFbinding site dependent transcription, suggesting that these mutants will be useful for investigating the biological functions of CaRF-dependent transcription.

\section{CaRF expression in the CNS}

We were able to use the Carf KO mice to validate our CaRFspecific antibody (Fig. 2A); therefore, we first sought to establish the distribution of CaRF protein expression in the CNS. In the adult brain, CaRF immunoreactivity is present at similar levels in nuclear extracts from all regions surveyed including cortex, hippocampus, striatum, brainstem, and cerebellum (Fig. 3A). Because these extracts do not allow us to distinguish whether CaRF is expressed in neurons, glia, or both, we dissociated embryonic mouse brains and cultured the cells under conditions that yield 


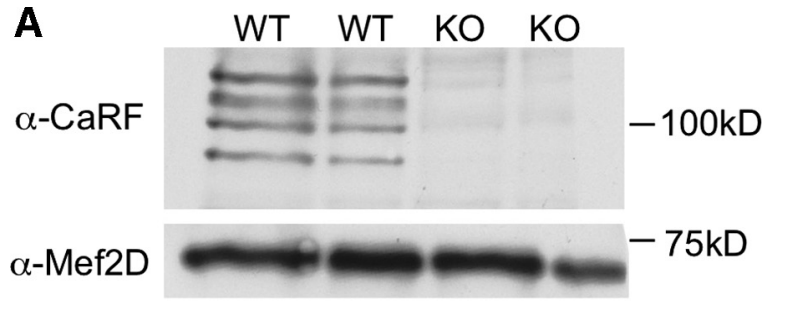

B C
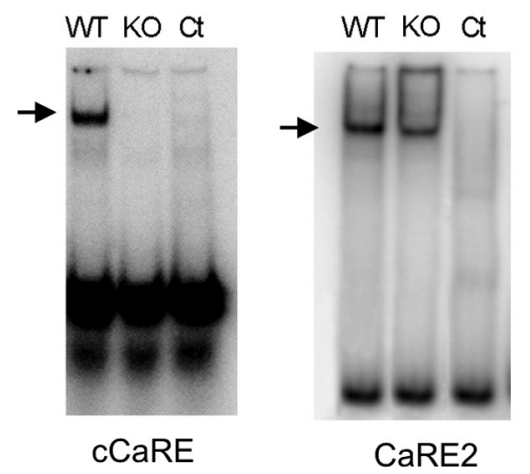

D

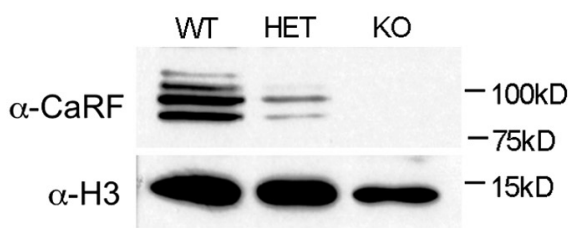

Figure 2. Carf exon $8 \mathrm{KO}$ mice lack nuclear CaRF protein and CaRF-dependent transcription. $A$, Western blot of nuclear extracts from brains of CarfWT and Carf KO mice. Ten micrograms of nuclear extract were separated by SDS-PAGE and transferred to PVDF membrane for probing with antibodies against $\mathrm{CaRF}$ and the neuronal transcription factor MEF2D. Four immunoreactive bands spanning $85-100 \mathrm{kDa}$ are seen in the WT lanes and absent in the KO lanes. MEF $2 \mathrm{D}$ is shown as a loading control. B, C, EMSA with nuclear extracts from neurons of Carf WT and KO mice. One microgram of nuclear extract was incubated with $50 \mathrm{fmol}{ }^{32} \mathrm{P}$ labeled DNA probes containing either a high-affinity CCaRE $(\boldsymbol{B})$ or a USF1/2 binding element from the $B d n f$ gene (CaRE2) (C) (Chen et al., 2003). The specificity of slowly migrating bands was determined by competition of the complex with a 100 -fold molar excess of unlabeled probe $(\mathrm{Ct})$. Specific retarded bands are marked with an arrow. $\boldsymbol{D}$, Western blot of CaRF expression in cultured embryonic fibroblasts from CarfWT, HET, and KO mice. Ten micrograms of nuclear extract were separated by SDS-PAGE and transferred to PVDF for probing with antibodies against CaRF. Histone $\mathrm{H} 3$ is shown as a loading control.

highly enriched populations of either neurons or glial cells. Although Carf mRNA and CaRF protein (data not shown) are detectable under both culture conditions, Carf mRNA is expressed at significantly higher levels in neuronally enriched cultures compared with glia (neurons, $100 \pm 15 \%$; glia, $26 \pm 5 \%$; $p=0.003$ ) To confirm that CaRF protein is expressed in neurons, we made cortical cultures from P0 brains of Carf WT or KO mice and performed double immunostaining for $\mathrm{CaRF}$ and the neuronal marker protein MAP2 (Fig. 3B). MAP2-expressing cells show intense nuclear CaRF immunoreactivity that is absent from MAP2-positive cells in the Carf KO cultures, further validating the nuclear localization and expression of CaRF in neurons.

Finally, to determine whether expression of CaRF changes during development, we harvested both RNA and nuclear extracts from mouse cortex at a series of time points across embryonic and postnatal development. Intriguingly, we found that CaRF expression changes significantly across developmental time, reaching its highest levels in the first 2 weeks after birth. Expression of CaRF then declines, although it persists at levels

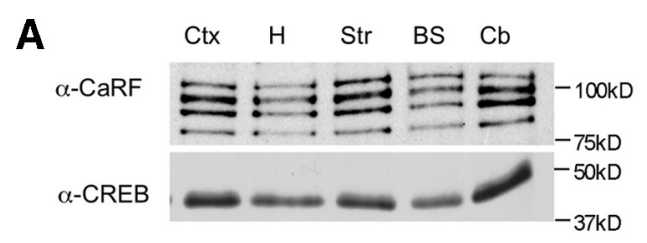

B
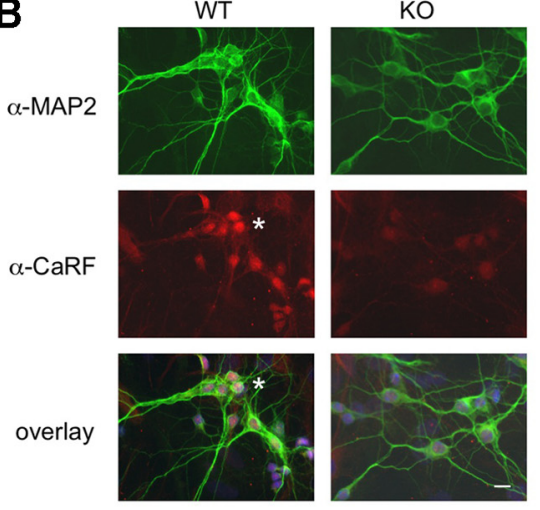

C

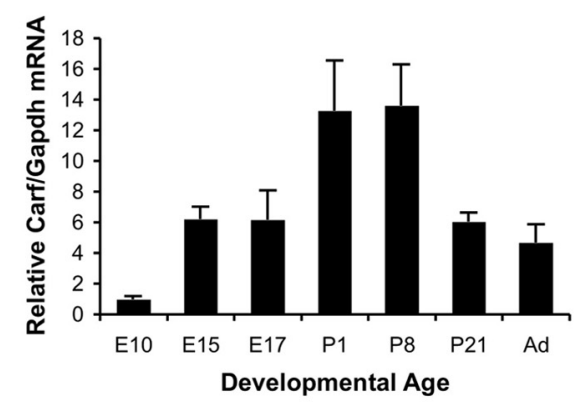

D

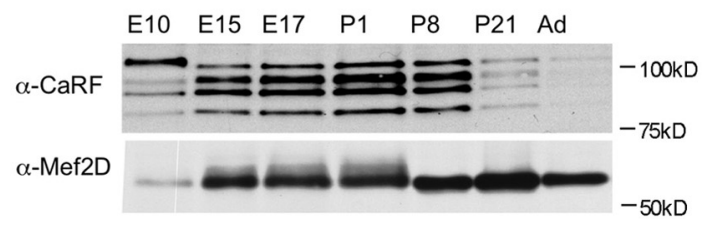

Figure 3. Distribution and developmental regulation of CaRF in the CNS. $A$, Western blot of CaRF expression in nuclear extracts from adult brain regions. Nuclear extract $(10 \mu \mathrm{g})$ was loaded for each region. Ctx, Cortex; $\mathrm{H}$, hippocampus; Str, striatum; BS, brainstem; $\mathrm{Cb}$, cerebellum. CREB is shown as a control for comparison. $\boldsymbol{B}$, Double immunostaining of cortical neuron cultures for CaRF and the neuronal marker MAP2. P0 plus 10DIV Carf WT or K0 neurons on PDL-coated coverslips were incubated with antibodies against CaRF (red) and MAP2 (green). Nuclei were labeled with Hoeschst in blue. Bright CaRF immunoreactivity is visible in the nuclei of MAP2-positive cells (white asterisk) in WT cultures, but is not present in KO cultures. Scale bar, $10 \mu \mathrm{m}$. C, Carf mRNA expression from brain at different developmental ages. Ad, Adult. Expression was normalized to the housekeeping gene Gapdh and is depicted as the fold change relative to expression at E10. Error bars indicate SEM. D, Western blot of CaRF protein expression in whole brain nuclear extracts harvested at different developmental ages. Nuclear extract (10 $\mu \mathrm{g}$ ) was loaded into each lane. MEF2D is shown for comparison.

well above detection threshold into adulthood (Fig. 3C,D). Overall these expression data support a role for CaRF in CNS neurons, and they suggest that CaRF may be of particular importance during early postnatal development.

\section{Brain-region selective role for CaRF in regulation of}

Bdnf expression

CaRF was first identified as a transcription factor based on its affinity for a neuronal- and calcium-selective response element (CaRE1) in promoter IV of the Bdnf gene (Tao et al., 2002). Consistent with the in vitro evidence that CaRF can act as a CaRE1-dependent transcriptional activator of $B d n f$ promoter IV, 
A

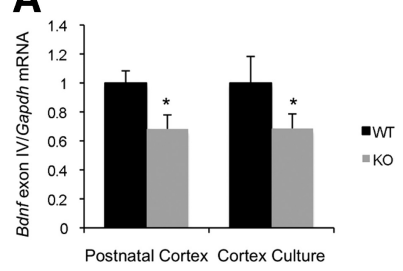

B

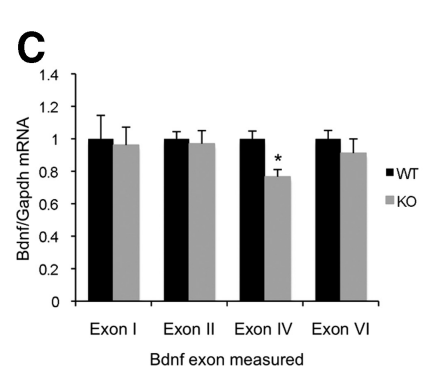

D

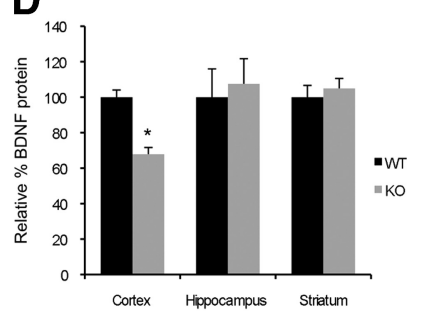

Figure 4. Expression of Bdnf exon IV and BDNF protein is reduced in Carf KO cortex. $\boldsymbol{A}, B d n f$ exon IV mRNA expression in cortex dissected from CarfWT and KO mice during the first 2 weeks of postnatal life or from PO cortex cultures that were made from individual WT or KO siblings of HET by HET crosses. Cultured neurons were treated with $1 \mu \mathrm{M}$ TTX overnight before mRNA harvesting. Gene expression is normalized to Gapdh to control for sample handling and results are scaled to the average value of the WT sample (WT average, 1; postnatal cortex, $n=7$ WT, 6 $\mathrm{KO}$; PO cortex culture, $n=3$ WT, 4 KO). $\boldsymbol{B}, \mathrm{KCl}$-dependent induction of $B d n f$ exon IV expression in CarfWT and $K O$ neurons cultured as in $\boldsymbol{A}$. Membrane depolarization was induced by addition of $55 \mathrm{~mm}$ extracellular $\mathrm{KCl}$ for 1,3 , or $6 \mathrm{~h}$ before mRNA harvesting. $n=2 \mathrm{WT}$ and $3 \mathrm{KO}$ at each time point. C, Expression of Bdnf exon I-, II-, IV-, or VI-containing mRNA transcripts in cerebral cortex dissected from adult Carf WT and K0 mice 2-6 months of age. $n=8$ WT and $10 \mathrm{KO}$. $D, B D N F$ protein expression in frontal cortex, hippocampus, or striatum dissected from adult Carf WT or KO mice. Results are scaled relative to the average WT level in each tissue (WT average, $100 \%$; frontal cortex, $n=8 \mathrm{WT}, 9 \mathrm{KO}$; hippocampus, $n=3 \mathrm{WT}, 3 \mathrm{KO}$; striatum, $n=7 \mathrm{WT}, 8 \mathrm{KO}$. Error bars indicate SEM. ${ }^{*} p<0.05$.

we found that $B d n f$ exon IV levels were significantly reduced in the cortex of postnatal $\mathrm{KO}$ mice compared with their WT littermates (WT, $100 \pm 8 \%$; KO, $68 \pm 9 \%$ ) (Fig. 4A), confirming the involvement of $\mathrm{CaRF}$ in the regulation of $B d n f$ expression in vivo. To determine whether CaRF contributes to changes in transcription driven by the activation of intracellular calcium signaling pathways, we measured $B d n f$ exon IV mRNA expression in P0 cortical cultures either in the presence of TTX, which blocks action potential firing and evoked synaptic activity, or after membrane depolarization induced by the elevation of extracellular potassium $(\mathrm{KCl})$, which opens L-type voltage-gated calcium channels. In the presence of TTX, $B d n f$ exon IV levels were significantly reduced in $\mathrm{KO}$ compared with WT cultures (WT, $100 \pm 18 \%$; KO, $68 \pm 10 \%$ ) (Fig. $4 A$ ). Because the CaRE1 element is required for the induction of neuronal activity-dependent transcription from $B d n f$ promoter IV after $\mathrm{KCl}$-induced membrane depolarization (Tao et al., 2002), we anticipated that CaRF might be required for $B d n f$ transcription induced by this stimulus. However, we were surprised to find that in response to acute membrane depolarization, $B d n f$ exon IV expression was strongly induced in both Carf WT and $\mathrm{KO}$ neurons with a similar magnitude and time course (Fig. $4 B)$. Overall, these data further support a role for CaRF in transcriptional regulation of $B d n f$ promoter IV. However, they suggest that the requirement is stimulus specific and demonstrate that $\mathrm{CaRF}$ is dispensable for induction of $B d n f$ exon IV expression after acute membrane depolarization of cultured neurons.

Transcription of the $B d n f$ gene is complex; this locus contains at least eight promoters that are differentially regulated by distinct complexes of transcription factors (Aid et al., 2007; West, 2008). To determine whether Carf KO mice show a selective dis-

ruption of $B d n f$ transcripts arising from transcription initiated at promoter IV, where CaRF is hypothesized to be bound, we examined the expression of the four most highly expressed $B d n f$ splice variants (exon I-, II-, IV-, and VI-containing Bdnf mRNAs) (Timmusk et al., 1993; Aid et al., 2007) in samples from the cerebral cortex of adult Carf WT and KO mice. Bdnf exon IV expression was significantly reduced in samples from the cerebral cortex of adult KO mice compared with WT mice (WT, $100 \pm$ $5 \%$; KO, $76.6 \pm 4 \%$ ) (Fig. 4C), indicating that CaRF continues to contribute to $B d n f$ regulation in these neurons under conditions of ongoing synaptic activity in vivo. By contrast, we found no differences in expression of exon I-, II-, or VI-containing $B d n f$ transcripts between Carf WT and KO mice, indicating that the effects of the Carf KO on Bdnf mRNA expression are exon IV specific (Fig. 4C). These data are consistent with the hypothesis that $\mathrm{CaRF}$ is a direct activator of $B d n f$ promoter IV-dependent transcription in cortical neurons. Interestingly, when we measured $B d n f$ exon IV expression in the hippocampus, we found no significant difference between WT and KO mice (WT, $100 \pm 6 \%$; $\mathrm{KO}, 113 \pm .11 \% ; n=3 \mathrm{WT}, 3 \mathrm{KO} ; p=0.366)$. Hence, these data suggest that CaRF differentially contributes to expression of $B d n f$ in different brain regions.

Finally to determine whether these changes in Bdnf exon IV mRNA levels result in reduced BDNF protein expression, we measured BDNF by ELISA in brain lysates taken from the frontal cortex, hippocampus, or striatum of adult Carf mice. Consistent with our mRNA results, we found that BDNF protein levels were significantly reduced in samples of frontal cortex from Carf KO mice compared with their WT siblings (WT, $100 \pm 4 \%$; KO, $68 \pm$ 4\%) (Fig. 4D). However, we found no differences in BDNF levels in samples from the hippocampus or striatum. In total, these data demonstrate that CaRF contributes to region-, stimulus-, and exon-selective expression of $B d n f$ mRNA transcripts in vivo, and that $\mathrm{CaRF}$ is required for maintenance of normal BDNF protein levels in the frontal cortex of adult mice.

\section{Altered GABAergic synaptic protein expression in Carf KO mice}

Many activity regulated transcription factors contribute to the development and/or plasticity of synapses (Ramanan et al., 2005; Flavell et al., 2006; Lin et al., 2008). To determine whether mutation of Carf affects synapses, we first quantified expression of a panel of GABAergic and glutamatergic synaptic marker proteins by Western blotting in lysates from different regions of Carf WT and $\mathrm{KO}$ brains. No significant differences were found between WT and KO mice in the frontal cortex or hippocampus (data not shown). However Western blotting of striatal lysates revealed significantly increased expression in $\mathrm{KO}$ mice of three proteins that are concentrated at GABAergic synapses (Fig. 5A,B): the presynaptic GABA synthesizing enzyme GAD-65 (1.8-fold increase in $\mathrm{KO}$ vs WT; $p=0.001$ ), and the postsynaptic $\mathrm{GABA}_{\mathrm{A}}$ receptor $\beta 2 / 3$ (6.4-fold increase in KO vs WT; $p=0.0003)$ and $\gamma 2$ subunits (2.8-fold increase in KO vs WT; $p=0.006)$. By contrast, we found no significant differences between genotypes in the expression of three proteins enriched at glutamatergic synapses: NR1 $(p=0.610)$, SAPAP3 $(p=0.463)$, and PSD-95 $(p=$ $0.882)$. Similarly, there were no changes in expression of DARPP-32 ( $p=0.290)$, a signaling protein highly enriched in striatal medium spiny neurons; GAD-67 ( $p=0.601)$, a marker of GABAergic interneurons; or synaptophysin ( $p=0.913)$, an integral synaptic vesicle protein common to all synapses.

To determine whether this increase in the expression of GABAergic synaptic proteins is associated with an increase in the 
expression of these proteins at synapses, we performed immunohistochemistry on coronal brain sections through the ventral striatum of Carf WT and KO mice and quantified the intensities of immunolabeling at synaptic punctae (Fig. 5C,D). Consistent with our observations in cell lysates, the intensity of GAD-65 immunoreactivity was significantly increased at synaptic punctae in $\mathrm{KO}$ mice $\left(\mathrm{WT}, 1.51 \pm 0.23 \times 10^{6} ; \mathrm{KO}\right.$, $\left.2.45 \pm 0.36 \times 10^{6} ; p=0.034\right)$, whereas the intensity of synaptophysin immunoreactivity was unchanged between genotypes (WT, $15.33 \pm 1.589 \times 10^{6} ; \mathrm{KO}$, $\left.14.59 \pm 1.026 \times 10^{6} ; p=0.697\right)$. We also observed an increase in the total number of GAD-65 expressing synaptic punctae in KO compared with WT mice (WT, $427 \pm$ $50 ; \mathrm{KO}, 640 \pm 79 ; p=0.031)$. This result could indicate that Carf KO mice have an increased number of GABAergic synapses, or it could arise as a secondary consequence of the overall increased intensity of GAD-65 immunoreactivity, which may allow us to detect smaller punctae. Supporting this latter interpretation, no difference was observed between genotypes in the total number of synapses as measured by counting punctae of synaptophysin immunoreactivity (WT, $2923 \pm 171 ; \mathrm{KO}, 2947 \pm 111 ; p=0.905)$. Together, these data reveal that expression of both pre- and post-synaptic components of GABAergic synapses are significantly upregulated in the striatum of Carf KO mice compared with their WT littermates.

Behavioral analyses of Carf KO mice Although CaRF is expressed during embryogenesis and in multiple tissues (Tao et al., 2002), Carf WT, HET, and KO mice are born at the expected Mendelian frequencies (data not shown), indicating that this protein is not essential for early development. Carf KO mice are both viable and fertile, and brains of adult Carf KO mice appear grossly anatomically normal compared to their WT siblings (data not shown). To quantitatively assess a broad range of neurobehavioral phenotypes, two investigators blind to the genotypes of the mice evaluated Carf WT, HET, and KO mice using the SHIRPA phenotypic screen. This analysis can suggest the presence of neurological abnormalities by screening for defects in gait or posture, motor control and coordination, gross changes in sensory function, alterations in excitability and aggression, and changes in salivation, lacrimation, piloerection, defecation, muscle tone, and temperature. It also provides a gross measure of analgesia (Rogers et al., 1997). No notable differences were found on any measure in this screen across Carf genotypes (supplemental Table S2, available at www.jneurosci.org as supplemental material). These data indicate that Carf KO mice have no gross physical, sensory, or motor
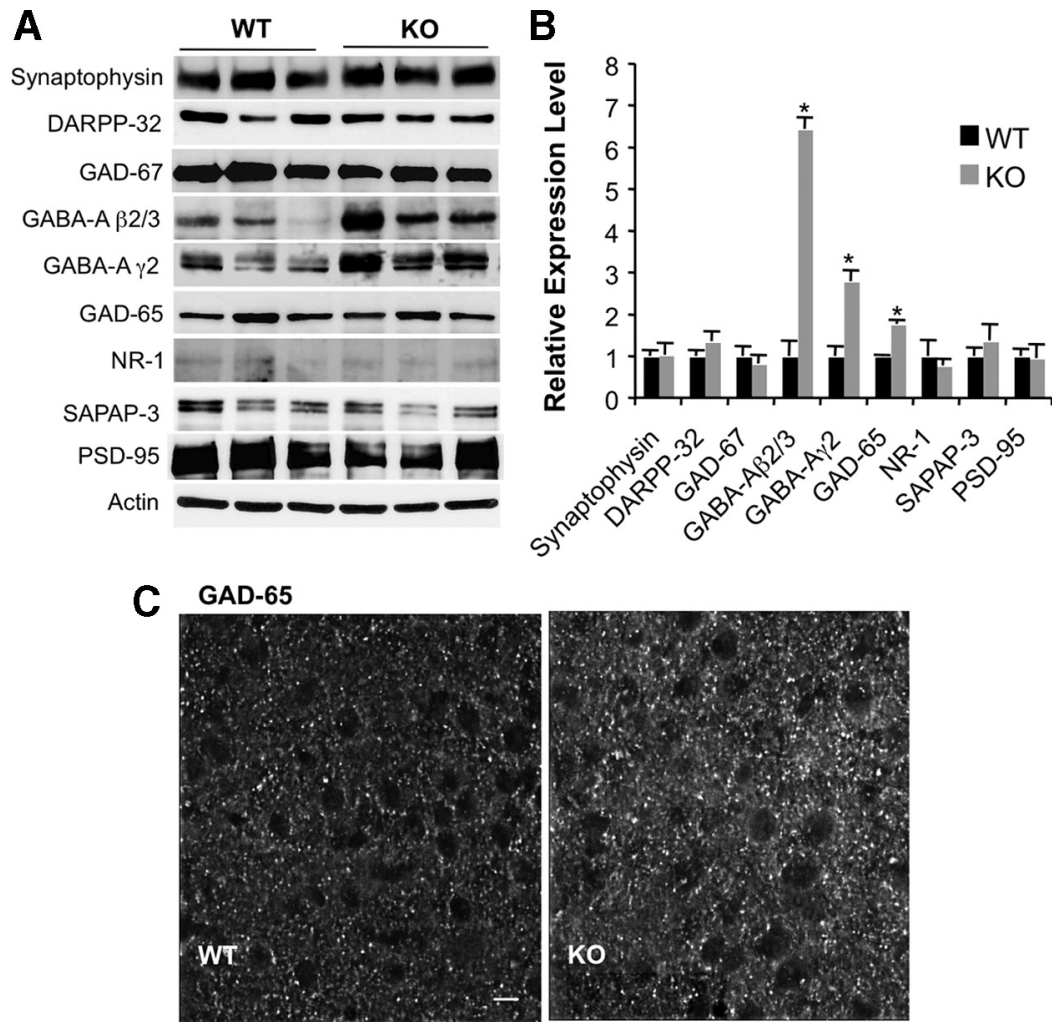

D Synaptophysin
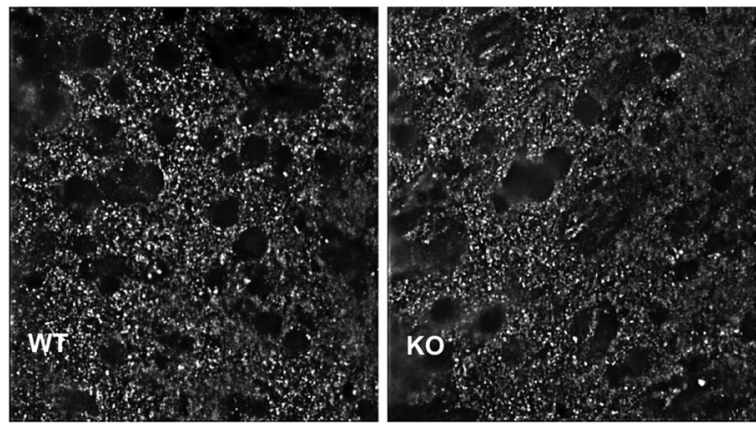

Figure 5. Increased expression of GABAergic synaptic proteins in the striatum of ( Carf KO mice. A, Striata were freshly dissociated from coronal sections of 3 Carf WT (left three lanes) and $3 \mathrm{KO}$ (right three lanes) adult mouse brains, and then the samples were weighed and homogenized in Laemli SDS sample buffer. Twenty micrograms of total lysate were used for immunoblotting with the indicated antibodies, and immunoreactivities were visualized with ECL. B, Quantification of the data shown in $A$. WT samples are shown in black, and $\mathrm{KO}$ in gray. Multiple film exposures were taken for each immunoblot and scanned, and then band density in each lane was quantified using ImageJ. Expression was normalized to actin for each sample. $C$ ) Representative images of GAD-65 values closest to the mean for each genotype. Scale bar, $10 \mu \mathrm{m}$. $\boldsymbol{D}$, Representative images of synaptophysin staining in coronal sections as in $C$. Error bars indicate SEM. ${ }^{*} p<0.05$ compared with WT.

deficits that would impact interpretation of their performance on more complex behavioral tasks.

\section{Spatial learning and memory}

Considerable evidence suggests that several aspects of learning and memory rely on the regulation of new gene transcription (Nguyen et al., 1994; Korzus et al., 2004; Ramanan et al., 2005). To test multiple distinct aspects of memory acquisition and retention, we trained Carf WT and KO mice on several cognitive tasks. First, to assess spatial learning and memory, we measured the performance of Carf WT, HET, and KO mice in the Morris water maze. Mice were trained over a period of $7 \mathrm{~d}$, and their latencies to locate a hidden platform were recorded. During days 

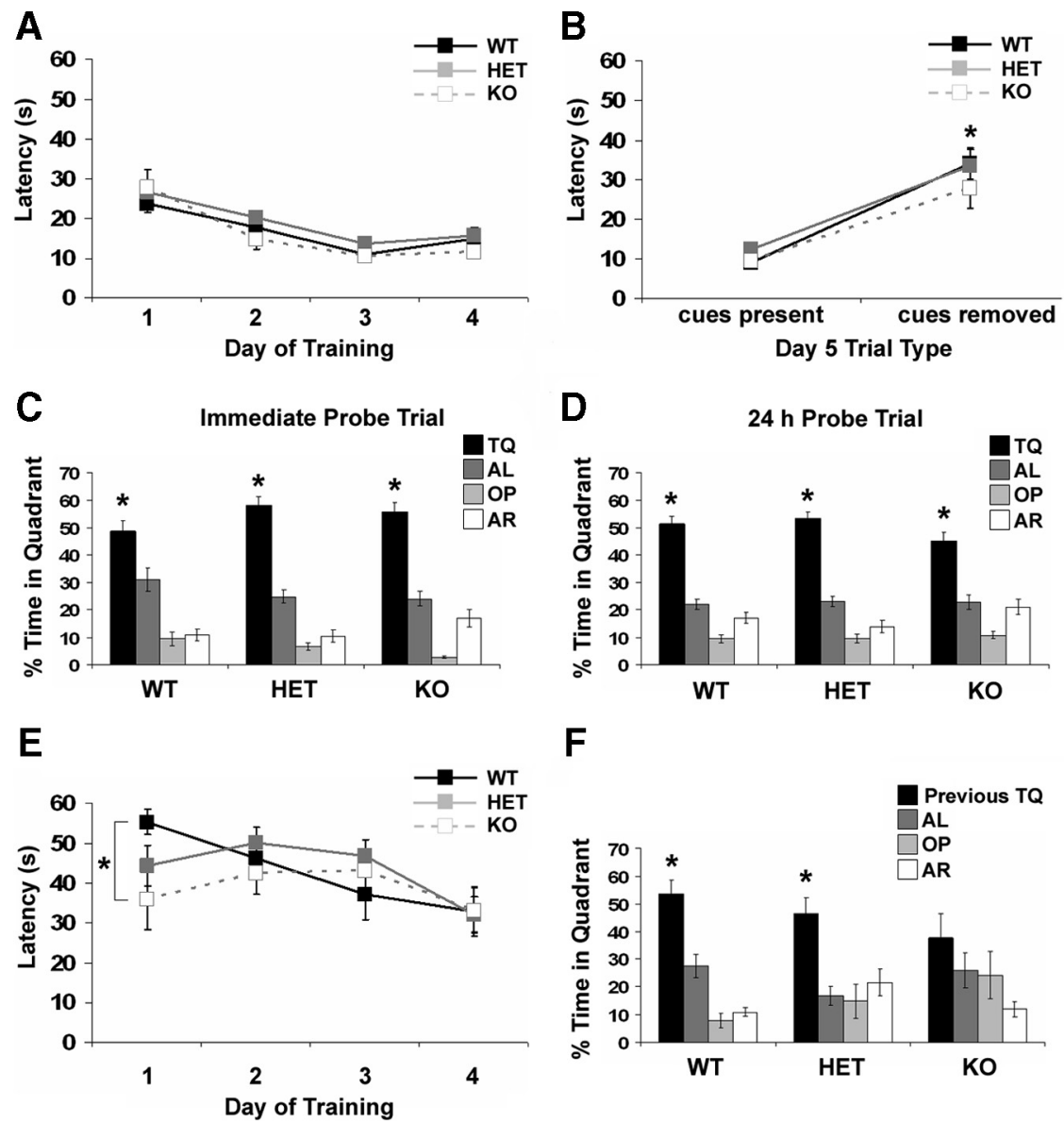

$\mathbf{F}$

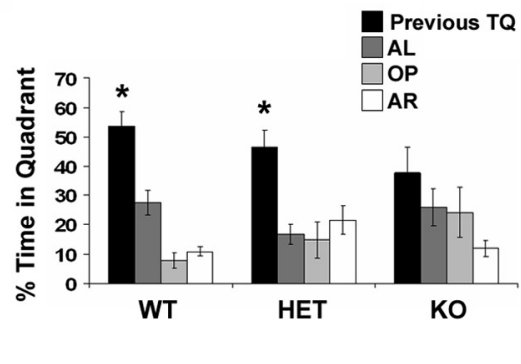

G

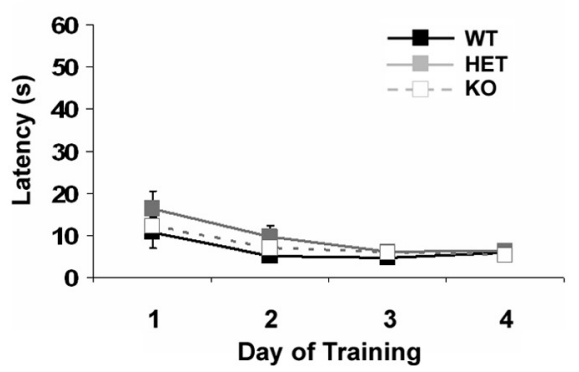

Figure 6. Carf KO mice show normal acquisition of hippocampal-dependent spatial learning and memory, and enhanced performance on a reversal learning task. $A$, Mean latency to escape to a hidden platform is shown for Carf WT, HET, or KO mice over the first four consecutive training days. $\boldsymbol{B}$, Mean latency to escape to a hidden platform on day 5 of training is shown for (arf WT, $\mathrm{HET}$, and $\mathrm{KO}$ mice when spatial cues are visible (cues present) or when curtain has been pulled around the pool (cues removed). C, Percentage of total swimming time ( $60 \mathrm{~s}$ ) spent in each quadrant of the pool when the platform was removed and mice were tested immediately after training. TQ, Target quadrant (black); AL, adjacent right quadrant (dark gray); OP, opposite quadrant (light gray); AR, adjacent right quadrant (white). D, Percentage of total swimming time (60 s) spent in each quadrant of the pool when the platform was removed and mice were tested after a $24 \mathrm{~h}$ retention interval. $\boldsymbol{E}$, Latency to escape to hidden platform during four daily trials of reversal learning over $4 \mathrm{~d}$. $\boldsymbol{F}$, Percentage of time spent swimming in each quadrant of the pool on the first day of reversal learning with a new hidden platform location. Quadrants are labeled with respect to the position of the previous target quadrant (previous TQ, black). G, Latency to escape to a visible platform over $4 \mathrm{~d}$ of training after reversal learning. Error bars indicate SEM. ${ }^{*} p<0.05$.

1-4 of training, all three genotypes learned to locate the hidden platform with similar reductions in mean escape latencies (Fig. $6 A)$. This was confirmed by RMANOVA with a significant main effect of day $\left(F_{(3,117)}=21.55 ; p<0.001\right)$, and no significant day by genotype interaction was evident $(F<1)$. On day 5 , mice were first given three training trials with extramaze cues, followed by one curtain trial that occluded all extramaze cues. A mean latency was recorded for the extramaze cue trials for each mouse. Only a single curtain trial was administered to discourage mice from changing to an alternate search strategy. A 2 (trial type) by 3 (genotype) mixed ANOVA revealed a significant main effect of trial type $\left(F_{(1,39)}=58.38\right.$; $p<0.001)$, confirming that when spatial cues were removed from the task arena on day 5, all three genotypes similarly increased their swim latencies to the platform (Fig. 6B). Thus, all mice were using spatial cues when navigating the maze.

To test the ability of the mice to remember the spatial location of the hidden platform after training, mice were administered an immediate and a $24 \mathrm{~h}$ probe trial with the platform removed. Mice were allowed to swim freely for $60 \mathrm{~s}$, and the amount of time spent searching each quadrant was assessed. For both the immediate and $24 \mathrm{~h}$ probe trials, separate RMANOVAs for each genotype revealed a main effect of quadrant for each genotype for each probe (WT: immediate, $F_{(3,27)}=$ $25.08, p<0.001 ; 24 \mathrm{~h}, F_{(3,27)}=23.57, p<$ 0.001; HET: immediate, $F_{(3,57)}=55.90$, $p<0.001 ; 24 \mathrm{~h}, F_{(3,57)}=74.88, p<0.001$; KO: immediate, $F_{(3,33)}=68.68, p<0.001$; $\left.24 \mathrm{~h}, F_{(3,33)}=54.78, p<0.001\right)$. Post hoc tests revealed that all three genotypes spent a significantly greater amount of time in the target quadrant compared to the other pool quadrants for both probe trials (all $p<0.05$ ) (Fig. 6C,D), confirming that all mice had formed a spatial memory of the platform location.

To test the ability to learn a new spatial location, mice were given four trials of reversal learning in the water maze on day 6 . A two-way mixed ANOVA revealed a main effect of trial where there was an overall decrease in latencies across trials $1-4\left(F_{(3,117)}=5.05\right.$; $\left.p<00.01\right)$. However, inspection of the means revealed that KO mice did not progressively change latency over repeated trials, as was demonstrated by both WT and HET mice (Fig. $6 E$ ). Indeed, separate RMANOVAs revealed a significant effect of trial for WT mice $\left(F_{(3,27)}=5.37 ; p<00.01\right)$ and HET mice $\left(F_{(3,57)}=4.12 ; p<0.01\right)$, but not for $\mathrm{KO}$ mice $(F<1)$. Interestingly, $\mathrm{KO}$ mice also had significantly shorter latencies on the first trial than WT mice $(p<0.05)$, with WT mice taking, on average, nearly the entire $60 \mathrm{~s}$ to locate the new platform for the first time. We therefore investigated the performance of mice on the first trial of reversal learning and examined how much time each mouse spent searching for the platform in each quadrant. Separate RMANOVAs for each genotype revealed a main effect of quadrant for WT mice $\left(F_{(3,27)}=18.97 ; p<0.001\right)$ and HET mice $\left(F_{(3,57)}=7.10 ; p<0.001\right)$, whereas WT and HET mice spent 


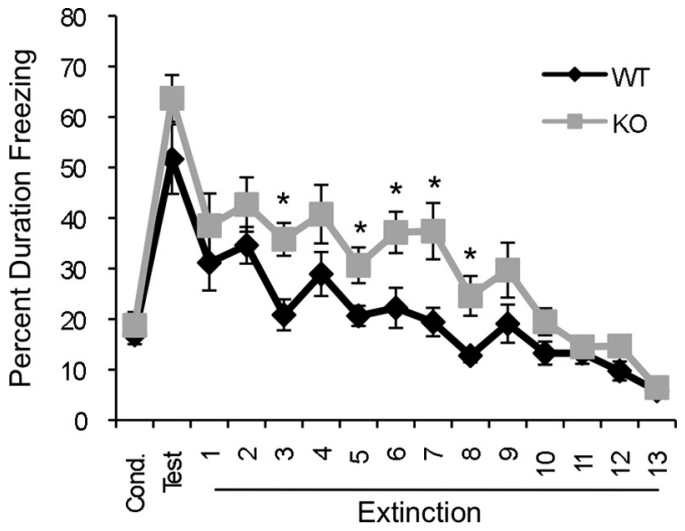

Figure 7. Impaired extinction of contextual fear conditioning in Carf KO mice. On day 0, 11 KO and 7 WT mice were shocked in a novel context (Cond.), and $24 \mathrm{~h}$ later, context-cued retention of the fear memory was measured by returning the animals to the same context (Test). Extinction of fear conditioning was run over 13 consecutive days. The average percentage of total time spent freezing over the 5 min test period is graphed for each day. Points indicate means, and error bars show SEM. * $p<0.05$ for KO compared with WT on a given test day.

significantly more time searching in the quadrant that held the previous platform location (Fig. $6 F$ ). In contrast, there was no effect of quadrant for $\mathrm{KO}$ mice, suggesting that unlike WT and HET mice, KO mice did not perseverate on the previously learned platform location while searching for the new platform location for the first time.

Finally, on day 7, mice were tested on a visible platform version of the water maze task to ensure that all mice were capable of locating the platform and were motivated to escape the pool. All mice located the visible platform with comparable latencies to those of the spatial learning water maze task, and all mice showed decreased latencies across trials 1-4 with the platform in a different locations on each trial (main effect of trial, $F_{(3,117)}=$ 8.15; $p<0.001$ ) (Fig. 6G).

These data indicate that the Carf KO and HET mice can learn and remember for at least $24 \mathrm{~h}$ the spatial location of a hidden platform in the water maze, they rely on extramaze spatial cues to guide their navigation, and they are as motivated to escape onto a platform in the water maze as are their WT littermates. Carf KO mice do, however, show a different pattern of searching behavior at the beginning of learning a new platform location, because compared to WT and HET mice, they do not initially perseverate on the previously learned platform location.

\section{Contextual fear conditioning and extinction}

Similar to the use of the Morris water maze to test spatial learning and memory, contextual fear conditioning can be used to test distinct phases of acquiring, remembering, and relearning emotional memories (Fanselow and Poulos, 2005). Carf WT and KO mice were conditioned on day 1 , tested in contextual fear conditioning on day 2 , tested in cued fear conditioning on day 3 , and subjected to extinction on days $4-16$. Percentage of time freezing (Fig. 7) was used as an index of emotional memory in the mice. After the CS-UCS pairing at conditioning, WT and KO mice exhibited similar levels of freezing on day 0 , indicating that the genotypes had similar sensitivities to the foot shock. In contextual testing, no genotype differences were discerned. Similarly, in cued testing, no differences were observed between WT and KO mice (data not shown); however, before presentation of the CS, levels of freezing were significantly elevated above baseline, sug- gesting that the mice generalized the shock memory beyond the paired context. In contextual fear extinction, Carf $\mathrm{KO}$ mice did not as readily extinguish this response when compared to WT controls. RMANOVA for time spent freezing during the $14 \mathrm{~d}$ of context testing showed a marked within-subjects effect for time $\left(F_{(13,221)}=31.033 ; p<0.001\right)$ indicating that freezing responses slowly attenuated over time. However, whereas the withinsubjects effects for the test day by genotype interaction was not significant, the nonlinear quadratic trend for within-subject contrasts for the test day by genotype interaction was significant $\left(F_{(1,17)}=7.656 ; p<0.013\right)$. In addition, the between-subjects effects for genotype were also significant $\left(F_{(1,17)}=7.679 ; p<\right.$ $0.019)$. Bonferroni-corrected pairwise comparisons revealed that the $\mathrm{KO}$ animals showed higher levels of freezing on test days 4,6 , 7,8 , and $9(p<0.039)$ compared to WT controls. To examine the pattern of extinction within each genotype, the level of freezing across days was analyzed relative to that observed on the first day of testing. Interestingly, both WT and Carf KO mice showed significant reductions on context test days 4 through $14(p<$ 0.032 ) relative to test day 1 . Together, these findings show that like their WT littermates, Carf KO mice can both learn and extinguish a conditioned fear response; however, the KOs show a significant delay in extinction learning.

\section{Novel object recognition}

Finally, we examined the Carf WT and KO mice for recognition memory in a novel object recognition task (Clark and Martin, 2005). In this test, mice are habituated in a single trial to a chamber with two identical objects. One of the familiar objects is then replaced with a novel object $30 \mathrm{~min}$ after training, and preference for the novel object is assessed as an indicator of short-term memory. The animals are later examined at $24 \mathrm{~h}$ and $10 \mathrm{~d}$ for long-term and remote memory, respectively.

During adaptation to the arena, WT and KO mice demonstrated similar levels of exploration and locomotion (data not shown), and during object training on day 1, both WT and Carf KO similarly explored the two training objects (WT, 197.5 \pm 17.5 interactions, $142.6 \pm 22.1 \mathrm{~s}$; KO, $194.5 \pm 19.8$ interactions, $129.5 \pm 17.8 \mathrm{~s})$. When examined for short-term memory, WT mice (Fig. $8 \mathrm{~A}$ ) showed a strong preference for the novel object during the first $3 \mathrm{~min}$ of testing, and this preference rapidly decreased over the final 6 min of testing. By comparison, the Carf KO mice showed little preference for the novel object during the first 6 min of testing, but in the final 3 min exhibited a pronounced preference for the novel object. RMANOVA for the short-term memory test did not reveal a significant withinsubjects effect for time, but did show a significant within-subjects effect for the time by genotype interaction $\left(F_{(2,28)}=15.896 ; p<\right.$ $0.001)$. Bonferroni-corrected pairwise comparisons showed that in the WT mice had a greater preference for the novel object during the first $3 \mathrm{~min}$ of testing compared to KOs $(p<0.007)$, but that in the final 3 min of testing, it was the KO mice that had a stronger preference for the novel object relative to WT controls $(p<0.001)$. It is important to note that the $0-3 \mathrm{~min}$ preference score for WT and the 6-9 min preference score for KO mice did not differ from one another $(p=0.844)$, indicating there was no difference in the short-term recognition of the novel object by the Carf mutants relative to controls. Moreover, total time spent with the objects (supplemental Table S3, available at www.jneurosci. org as supplemental material) and the frequency of interactions with the novel and familiar objects (supplemental Table S4, available at www.jneurosci.org as supplemental material) did not reveal any differences as a function of genotype or time. These data 

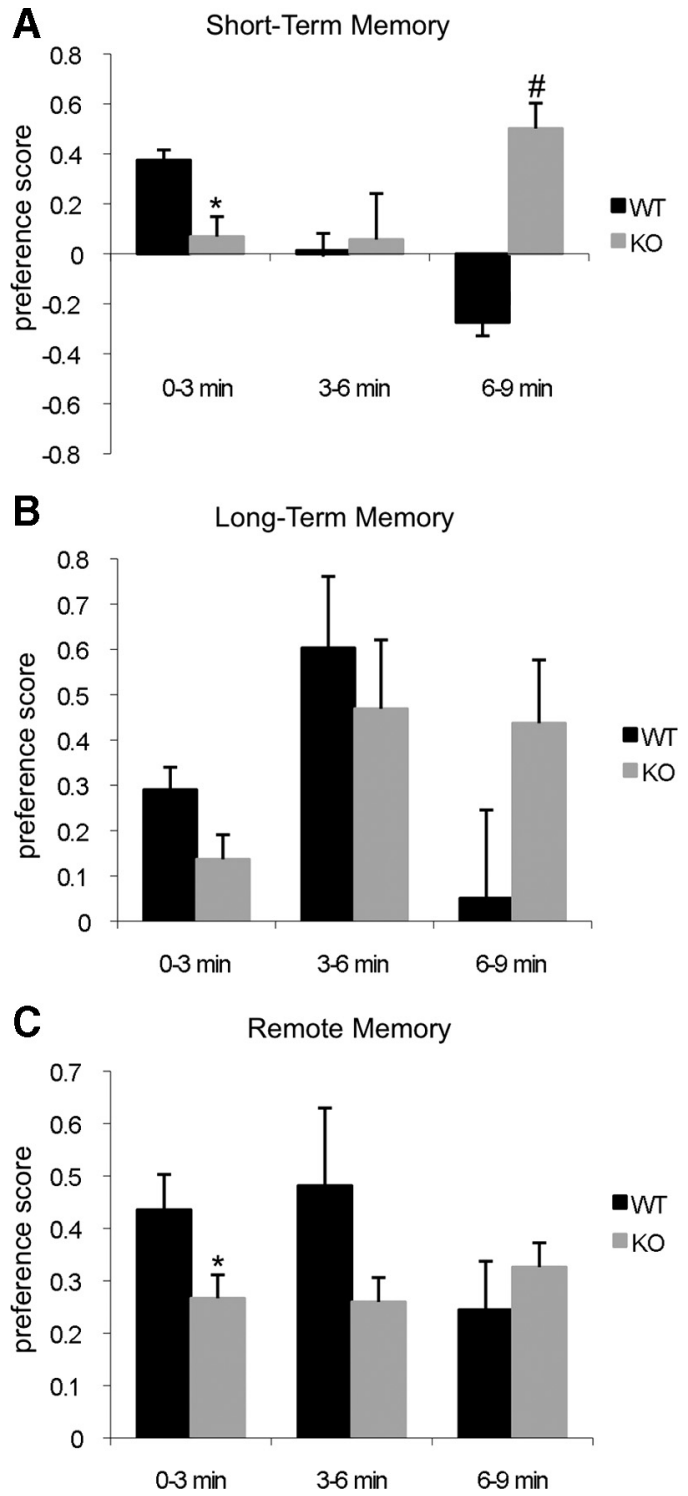

Figure 8. Impaired remote memory for novel object recognition in Carf KO mice. A, Preference for novel object when returned to the test arena $20 \mathrm{~min}$ after initial object exposure. $B$, Preference for novel object when returned to the test arena $24 \mathrm{~h}$ after initial object exposure. $C$, Preference for novel object when returned to the test arena $10 \mathrm{~d}$ after initial object exposure. Times of interactions and number of interactions are shown in supplemental Tables S3 and S4 (available at www.jneurosci.org as supplemental material). Error bars indicate SEM. $n=11 \mathrm{KO}$ and 7 WT mice. ${ }^{*} p<0.05$ compared with WT at $0-3$ min; ${ }^{\#} p<0.05$ compared with WT at $6-9$ $\min$.

provide further evidence that short-term memory is intact in the Carf mutants.

During long-term memory testing, WT and Carf $\mathrm{KO}$ mice (Fig. $8 \mathrm{~B}$ ) patterns of retention were similar during the first $6 \mathrm{~min}$ of testing, with WT and $\mathrm{KO}$ mice showing low preference scores during the first $3 \mathrm{~min}$ of testing and stronger preference scores during the 3-6 min interval. RMANOVA revealed a withinsubjects effect for time $\left(F_{(2,28)}=3.395 ; p<0.050\right)$, but no significant time by genotype interaction. The between-subjects test for genotype also did not reveal any significant effects for long-term preference scores. With regard to total time spent with the two test objects during long-term memory (supplemental Table S1, available at www.jneurosci.org as supplemental material), no genotype differences were observed. These analyses indicate that long-term recall between the Carf WT and KO mice is similar.
Examination of remote memory in the mice was conducted after $10 \mathrm{~d}$, at which time it is generally considered to be a test of cortical function (Frankland and Bontempi, 2005). During remote memory testing, $\mathrm{KO}$ mice showed a significant reduction in preference for the novel object relative to WT controls (Fig. 8C). Although a RMANOVA found no significant within-subjects effect for time, the time by genotype interaction was statistically significant $\left(F_{(2,28)}=3.614 ; p<0.040\right)$. Carf WT and $\mathrm{KO}$ mice markedly differed in their preference for the novel object during the first 3 min of testing ( $p<0.048$ ), and KO mice also showed a marginal reduction in preference at the $4-6$ min interval $(p<$ $0.064)$. During the first $3 \mathrm{~min}$ of remote memory testing, no differences were found between WT and KO mice for the time spent with the objects (supplemental Table S1, available at www. jneurosci.org as supplemental material). However, at the 4-6 and 7-9 min intervals, KOs spent more time with the objects compared to WT controls. Moreover, whereas WT mice reduced the time spent with objects during the final two intervals of testing compared to the first $3 \mathrm{~min}$, this reduction was not observed among the Carf $\mathrm{KO}$ animals. Interactions with novel and familiar objects (supplemental Table S2, available at www.jneurosci.org as supplemental material) also differed during this test for WT and mutants; controls had more interactions with the novel compared to familiar object during each of the three test intervals, whereas KOs had the same rate of interaction for novel and familiar objects during the course of testing. Moreover, $\mathrm{KO}$ mice had more interactions with the familiar object than WT controls. These data indicate that Carf KO mice show impairment in remote object recognition relative to their WT littermate controls. Together, the results of the object recognition testing show that compared to WT controls, Carf KO mice have intact short-term and long-term memory, but are deficient in cortical-regulated remote memory.

\section{Discussion \\ CaRF-dependent regulation of BDNF expression}

The identification of CaRF as a binding protein for the CaRE1 element in $B d n f$ promoter IV suggested that CaRF might be a physiologically relevant activator of $B d n f$ transcription (Tao et al., 2002). Consistent with this hypothesis, we now find that levels of $B d n f$ exon IV mRNA are significantly reduced in the cerebral cortex of Carf KO mice in vivo (Fig. 4). This disruption is selective for exon IV-containing $B d n f$ transcripts, supporting the hypothesis that association of CaRF with the CaRE1 element in promoter IV of the $B d n f$ gene directly enhances transcription from the exon IV start site. However, we find that this requirement for $\mathrm{CaRF}$ is brain region selective, as Carf $\mathrm{KO}$ mice show normal levels of $B d n f$ mRNA in the hippocampus. This regional selectivity is not caused by differential expression of CaRF, because we find CaRF protein expressed at similar levels in all of the brain regions we have tested. Our data also indicate that the requirement for CaRF is stimulus selective. $B d n f$ exon IV mRNA levels are reduced in Carf KOs under conditions of normal ongoing synaptic activity in vivo and after TTX-mediated blockade of evoked neurotransmission in cultured neurons. However, $\mathrm{CaRF}$ is dispensable for activity-dependent upregulation of $B d n f$ exon IV in response to membrane depolarization in cultured neurons. These data were somewhat surprising because the CaRE1 element, which CaRF binds, is required for activitydependent expression of $B d n f$ exon IV in response to membrane depolarization (Tao et al., 2002).

One possible explanation for the region- and stimulusselective requirements for CaRF may be that additional CaRE1- 
binding proteins can serve as effectors of this element. Functional redundancy among transcription factors is common (Blendy et al., 1996; Chen et al., 2003), and distinct binding proteins may contribute to the function of CaRE1 in different cellular contexts. Importantly, our data do not exclude the possibility that CaRF may contribute to stimulus-dependent $B d n f$ exon IV transcription under conditions other than those tested here. Membrane depolarization selectively activates gene expression through signaling pathways that are coupled to the opening of L-type voltage-gated calcium channels (Bading et al., 1993). By contrast, $B d n f$ exon IV transcription is activated by distinct intracellular signaling cascades following other kinds of stimuli such as synaptic NMDA-receptor activation (Zhang et al., 2007), BDNFtyrosine receptor kinase B signaling (Xiong et al., 2002), and cocaine treatment (Liu et al., 2006), and these signaling cascades could converge on distinct sets of CaRE1-binding proteins. Understanding the basis for the selective requirement for CaRF in region- and stimulus-specific $B d n f$ expression will open new windows into the intricate regulation of this important neural gene.

Importantly, although BDNF is an attractive candidate to underlie the synaptic and behavioral phenotypes of Carf KO mice, as a transcription factor, $\mathrm{CaRF}$ is likely to contribute to the expression of hundreds of gene products in addition to Bdnf. Using the anti-CaRF antibody developed here, we have recently performed chromatin immunoprecipitation followed by sequencing of coimmunoprecipitated genomic DNA to identify 176 sites of CaRF binding across the genome (A. E. West, unpublished observations). Characterization of this CaRF regulon will be an essential step toward a fuller understanding of the molecular mechanisms underlying the phenotypes in Carf KO mice.

\section{Roles for CaRF in GABAergic synapse development}

GABA is the major inhibitory neurotransmitter in the adult CNS, and by regulating the temporal patterns of pyramidal neuron firing, GABAergic neurotransmission contributes to complex aspects of network computation and neural circuit function (Sohal et al., 2009). Expression of several GABA receptor subunits is subject to modulation by environmental stimuli, and interestingly, changes in GABAergic synaptic composition have been suggested to contribute to stimulus-induced behavioral plasticity. For example, expression of the $\mathrm{GABA}_{\mathrm{A}}$ receptor $\beta 2$ and $\gamma 2$ subunits is increased in the amygdala coincident with extinction of fear conditioning (Heldt and Ressler, 2007), and neonatal maternal separation leads to persistent alterations in hippocampal GABA receptor subunit expression that are correlated with altered behavioral stress responses in adulthood (Hsu et al., 2003). We find that Carf KO mice have increased expression of three GABAergic synaptic proteins (GAD-65, GABA ${ }_{A} \beta 2 / 3$ and $\mathrm{GABA}_{\mathrm{A}} \gamma 2$ ) in the striatum while the number of synapses and the expression of several glutamatergic synaptic proteins remain unchanged (Fig. 5). GABA $\mathrm{A}$ receptors are pentamers, and most are composed of combinations of two $\alpha$ subunits, two $\beta$ subunits, and one $\gamma$ or $\delta$ subunit (Jacob et al., 2008). Differential subunit composition confers distinct pharmacology and physiology upon $\mathrm{GABA}_{\mathrm{A}}$ receptors, as well as regulating their subcellular distribution (Jacob et al., 2008). Thus, it is possible that these changes in synaptic protein expression we detect could alter GABAergic neurotransmission in the striatum of Carf KO mice. Future studies that address when these synaptic changes first arise during development and what functional consequences these alterations have for neuronal physiology will significantly inform our understanding of how CaRF-dependent transcription may modulate neural circuit function.

\section{Learning and memory changes in Carf $\mathrm{KO}$ mice}

The Morris water maze is a robust spatial learning task commonly used to identify deficits in learning and memory in genetically altered mice (Vorhees and Williams, 2006). Carf KOs performed as well as their WT and HET littermates in both the acquisition and the memory phases of this task. However, on the first day of reversal training the $\mathrm{KO}$ mice were able to find the new location significantly faster than WT or HET mice. Reversal learning in the Morris water maze can suggest procedural and cognitive flexibility (Crawley, 2007). Alternately, it may suggest that Carf KO mice have a weaker memory trace than WT mice, because they did not perseverate on the previously learned platform location. To begin to differentiate among these possibilities, we further assessed cognitive function in the Carf KOs using additional memory tests.

In the fear conditioning experiments, Carf KOs and WTs showed similar levels of immobility on the first day they were returned to the shock-paired context, suggesting that the KOs can learn this association. However upon repeated exposure to the context, Carf KOs extinguished their freezing responses more slowly than their WT littermates. Fear extinction is not simply forgetting of the fear memory, rather it is an active relearning process that appears to require function of several brain regions (Myers and Davis, 2007). Although the increased freezing during extinction by the Carf KO mice could suggest amygdala dysfunction, preliminary data on a small set of Carf WT and KO mice indicate that fear potentiated startle, a test of amygdala function, does not differ (data not shown). This suggests that delayed extinction in the Carf KOs may be more attributable to deficits in the plasticity of this learned response, rather than overactivation of the amygdala during the experiencing of an emotional event.

Extinction of fear conditioning is induced when the CS (in this case the context) is repeatedly presented in the absence of the UCS (the shock) (Myers and Davis, 2007). For the new lack of association between the CS and the UCS to be learned during extinction training, it is necessary that the animal accurately remember the previous expected relationship between these two stimuli. Thus, impaired extinction of fear conditioning could arise as a result of a weakened memory trace of the CS-UCS association that leads to generalization of fear responses. Consistent with the possibility that memory traces are less persistent in the Carf KO mice, we found that they had significantly impaired recognition of a novel object $10 \mathrm{~d}$ after training, even though their short- and long-term memory of the investigated object was not significantly different from that of WT mice. Interestingly, novel object recognition after $10 \mathrm{~d}$ in this test is thought to depend on transfer of the memory trace from the hippocampus to the cortex, as hippocampal lesions $10 \mathrm{~d}$ after training fail to disrupt remote memory (Frankland and Bontempi, 2005). Furthermore, BDNF is among the molecular mediators that are thought to play an essential role in fear extinction, as several different genetic manipulations that reduce expression of BDNF have all been associated with delayed fear extinction (Gorski et al., 2003; Heldt et al., 2007; Soliman et al., 2010). Together, these data raise the possibility that disruption of cortical function in the Carf $\mathrm{KO}$ mice, perhaps due in part to reduced cortical BDNF expression, may contribute to abnormal memory retention in these animals.

\section{References}

Aid T, Kazantseva A, Piirsoo M, Palm K, Timmusk T (2007) Mouse and rat BDNF gene structure and expression revisited. J Neurosci Res 85:525-535.

Angrand PO, Daigle N, van der Hoeven F, Scholer HR, Stewart AF (1999) 
Simplified generation of targeting constructs using ET recombination. Nucleic Acids Res 27:e16.

Bading H, Ginty DD, Greenberg ME (1993) Regulation of gene expression in hippocampal neurons by distinct calcium signaling pathways. Science 260:181-186.

Blendy JA, Kaestner KH, Schmid W, Gass P, Schutz G (1996) Targeting of the CREB gene leads to up-regulation of a novel CREB mRNA isoform. EMBO J 15:1098-1106.

Chen WG, West AE, Tao X, Corfas G, Szentirmay M, Sawadogo M, Vinson C, Greenberg ME (2003) Upstream stimulatory factors are mediators of calcium-responsive transcription in neurons. J Neurosci 23:2572-2581.

Clark RE, Martin SJ (2005) Interrogating rodents regarding their object and spatial memory. Curr Opin Neurobiol 15:593-598.

Crawley JN (2007) Mouse behavioral assays relevant to the symptoms of autism. Brain Pathol 17:448-459.

Fanselow MS, Poulos AM (2005) The neuroscience of mammalian associative learning. Annu Rev Psychol 56:207-234.

Farley FW, Soriano P, Steffen LS, Dymecki SM (2000) Widespread recombinase expression using FLPeR (flipper) mice. Genesis 28:106-110.

Flavell SW, Cowan CW, Kim TK, Greer PL, Lin Y, Paradis S, Griffith EC, Hu LS, Chen C, Greenberg ME (2006) Activity-dependent regulation of MEF2 transcription factors suppresses excitatory synapse number. Science 311:1008-1012.

Frankland PW, Bontempi B (2005) The organization of recent and remote memories. Nat Rev Neurosci 6:119-130.

Gorski JA, Balogh SA, Wehner JM, Jones KR (2003) Learning deficits in forebrain-restricted brain-derived neurotrophic factor mutant mice. Neuroscience 121:341-354.

Greer PL, Greenberg ME (2008) From synapse to nucleus: calciumdependent gene transcription in the control of synapse development and function. Neuron 59:846-860.

Heldt SA, Ressler KJ (2007) Training-induced changes in the expression of GABAA-associated genes in the amygdala after the acquisition and extinction of Pavlovian fear. Eur J Neurosci 26:3631-3644.

Heldt SA, Stanek L, Chhatwal JP, Ressler KJ (2007) Hippocampus-specific deletion of BDNF in adult mice impairs spatial memory and extinction of aversive memories. Mol Psychiatry 12:656-670.

Hong EJ, McCord AE, Greenberg ME (2008) A biological function for the neuronal activity-dependent component of $B d n f$ transcription in the development of cortical inhibition. Neuron 60:610-624.

Hsu FC, Zhang GJ, Raol YS, Valentino RJ, Coulter DA, Brooks-Kayal AR (2003) Repeated neonatal handling with maternal separation permanently alters hippocampal GABAA receptors and behavioral stress responses. Proc Natl Acad Sci U S A 100:12213-12218.

Jacob TC, Moss SJ, Jurd R (2008) GABA(A) receptor trafficking and its role in the dynamic modulation of neuronal inhibition. Nat Rev Neurosci 9:331-343.

Korzus E, Rosenfeld MG, Mayford M (2004) CBP histone acetyltransferase activity is a critical component of memory consolidation. Neuron 42:961-972.

Lakso M, Pichel JG, Gorman JR, Sauer B, Okamoto Y, Lee E, Alt FW, Westphal H (1996) Efficient in vivo manipulation of mouse genomic sequences at the zygote stage. Proc Natl Acad Sci U S A 93:5860-5865.

Lin Y, Bloodgood BL, Hauser JL, Lapan AD, Koon AC, Kim TK, Hu LS, Malik AN, Greenberg ME (2008) Activity-dependent regulation of inhibitory synapse development by Npas4. Nature 455:1198-1204.

Liu QR, Lu L, Zhu XG, Gong JP, Shaham Y, Uhl GR (2006) Rodent BDNF genes, novel promoters, novel splice variants, and regulation by cocaine. Brain Res 1067:1-12.
Myers KM, Davis M (2007) Mechanisms of fear extinction. Mol Psychiatry 12:120-150.

Nguyen PV, Abel T, Kandel ER (1994) Requirement of a critical period of transcription for induction of a late phase of LTP. Science 265:1104-1107.

Poo MM (2001) Neurotrophins as synaptic modulators. Nat Rev Neurosci 2:1-9.

Pulipparacharuvil S, Renthal W, Hale CF, Taniguchi M, Xiao G, Kumar A, Russo SJ, Sikder D, Dewey CM, Davis MM, Greengard P, Nairn AC, Nestler EJ, Cowan CW (2008) Cocaine regulates MEF2 to control synaptic and behavioral plasticity. Neuron 59:621-633.

Ramanan N, Shen Y, Sarsfield S, Lemberger T, Schutz G, Linden DJ, Ginty DD (2005) SRF mediates activity-induced gene expression and synaptic plasticity but not neuronal viability. Nat Neurosci 8:759-767.

Rodriguiz RM, Gadnidze K, Ragnauth A, Dorr N, Yanagisawa M, Wetsel WC, Devi LA (2007) Animals lacking endothelin-converting enzyme-2 are deficient in learning and memory. Genes Brain Behav 7:418-426.

Rogers DC, Fisher EM, Brown SD, Peters J, Hunter AJ, Martin JE (1997) Behavioral and functional analysis of mouse phenotype: SHIRPA, a proposed protocol for comprehensive phenotype assessment. Mamm Genome 8:711-713.

Schmalzigaug R, Rodriguiz RM, Bonner PE, Davidson CE, Wetsel WC, Premont RT (2009) Impaired fear response in mice lacking GIT1. Neurosci Lett 458:79-83.

Sohal VS, Zhang F, Yizhar O, Deisseroth K (2009) Parvalbumin neurons and gamma rhythms enhance cortical circuit performance. Nature 459:698-702.

Soliman F, Glatt CE, Bath KG, Levita L, Jones RM, Pattwell SS, Jing D, Tottenham N, Amso D, Somerville L, Voss HU, Glover G, Ballon DJ, Liston C, Teslovich T, Van Kempen T, Lee FS, Casey BJ (2010) A genetic variant BDNF polymorphism alters extinction learning in both mouse and human. Science 327:863-866.

Tao X, Finkbeiner S, Arnold DB, Shaywitz AJ, Greenberg ME (1998) $\mathrm{Ca}^{2+}$ influx regulates BDNF transcription by a CREB family transcription factor-dependent mechanism. Neuron 20:709-726.

Tao X, West AE, Chen WG, Corfas G, Greenberg ME (2002) A calciumresponsive transcription factor, $\mathrm{CaRF}$, that regulates neuronal activitydependent expression of BDNF. Neuron 33:383-395.

Timmusk T, Palm K, Metsis M, Reintam T, Paalme V, Saarma M, Persson H (1993) Multiple promoters direct tissue-specific expression of the rat BDNF gene. Neuron 10:475-489.

Vorhees CV, Williams MT (2006) Morris water maze: procedures for assessing spatial and related forms of learning and memory. Nat Protoc $1: 848-858$.

West AE (2008) Activity-dependent regulation of brain-derived neurotrophic factor transcription. In: Transcriptional regulation by neuronal activity (Dukek S, ed), pp 155-174. New York: Springer.

West AE, Griffith EC, Greenberg ME (2002) Regulation of transcription factors by neuronal activity. Nat Rev Neurosci 3:921-931.

Xiong H, Futamura T, Jourdi H, Zhou H, Takei N, Diverse-Pierluissi M, Plevy S, Nawa H (2002) Neurotrophins induce BDNF expression through the glutamate receptor pathway in neocortical neurons. Neuropharmacology 42:903-912.

Xu J (2005) Preparation, culture, and immortalization of mouse embryonic fibroblasts. Curr Protoc Mol Biol 28.21.21-28.21.28.

Zhang SJ, Steijaert MN, Lau D, Schutz G, Delucinge-Vivier C, Descombes P, Bading H (2007) Decoding NMDA receptor signaling: identification of genomic programs specifying neuronal survival and death. Neuron 53: $549-562$. 